\title{
Rectal Cancer - Staging and Surgical Approach
}

\author{
Pramateftakis Manousos-Georgios, Papadopoulos Vasileios, \\ Michalopoulos Antonios, Spanos Konstantinos, \\ Tepetes Konstantinos and Tsoulfas Georgios \\ Aristotle University of Thessaloniki \& University of Thessaly \\ Greece
}

\section{Introduction}

Pramateftakis $M G$

Worldwide, colorectal cancer is a major health problem. More than 1 million patients are diagnosed annually. It is the $3^{\text {rd }}$ most common cancer type and about half a million people die of the disease each year. Incidence is higher in more developed than less developed regions suggesting that lifestyle, dietary habits and environmental exposures, beyond genetic background, are responsible for the disease in the industrialized world.

In recent years significant knowledge has been acquired and applied in everyday clinical practice as far as rectal cancer is concerned. The treatment of rectal cancer has changed over the last two decades as far as surgical techniques, chemotherapy and radiotherapy are concerned. Effective surgery and modern radiotherapy combined with cytotoxic chemotherapy have improved survival rates (Nicholls \& Tekkis, 2008; Carlsen et al., 1998).

\section{Rectal cancer staging}

\section{Pramateftakis MG, Papadopoulos V, Michalopoulos A}

The assessment of a patient with rectal cancer involves the identification of disseminated disease and the locoregional staging of the tumor. Loco-regional factors which influence prognosis include T-stage, the lymph node status and the histological grade. Rectal cancer presents in 3 clinical categories. These are the early, the intermediate and the advanced lesions. The improvement of conventional diagnosis and the introduction of molecular screening advanced early diagnosis. Virtual colonoscopy, computed tomography (CT), magnetic resonance imaging (MRI), endorectal ultrasound (EUS) and positron emission tomography (PET) constitute a significant development to the diagnosis and staging of colorectal cancer (Kuhry et al, 2008). Endorectal ultrasound can demonstrate penetration of the rectal wall with high accuracy, but is poor at identifying the $\mathrm{N}$ stage. CT is useful for local extensive tumors particularly in identifying other organ involvement. MRI is accurate in determining the $\mathrm{T}$ stage but performs better in identifying the presence or absence of the circumferential margin involvement. In the last five years, preoperative staging has become more refined by advances in MRI imaging.

EUS seems to be an accurate method to stage rectal cancer preoperatively. The major drawback of EUS is that it is operator-dependent, but on the other hand it is easy and fast to 
perform, requires minimal patient preparation and it can be repeated without side effects. EUS based evaluation of rectal tumors provides an accuracy ranging from $62 \%$ to $92 \%$ for $\mathrm{T}$ staging and from $64 \%$ to $88 \%$ for N staging (Kim \& Wong, 2005).

Pelvic CT staging of rectal cancer is inferior to EUS with the accuracy for T staging ranging from $53 \%$ to $94 \%$ and for $\mathrm{N}$ staging from $54 \%$ to $70 \%$ (Harewood, 2005). MRI, especially with the use of endorectal coil, seems to be superior to CT for locoregional rectal cancer staging, with accuracy for $\mathrm{T}$ staging ranging from $66 \%$ to $92 \%$ and that for $\mathrm{N}$ staging rising over $95 \%$ (Chen et al., 2005).

A recent meta-analysis showed that EUS and MRI had similar sensitivity for T staging (94\%) but EUS had superior specificity compared to MRI ( $86 \%$ vs $69 \%)$. This study also showed that both EUS and MRI have poor sensitivity $(67 \%)$ and specificity (77\%) for $\mathrm{N}$ staging. However, there are reports in the literature stating that EUS may be overestimated, especially in small size series. Therefore, it seems that the accuracy of imaging methods for the N stage of rectal cancer needs further improvement (Harewood, 2005; Kwok et al., 2000). PET scanning has been used preoperatively to rule out metastatic disease in selected cases and postoperatively for the detection of recurrence or to evaluate response to treatment. It is reported that PET scan alters the conventional preoperative stage in nearly $40 \%$ of cases leading to modification of therapeutic strategies in $17 \%$ of patients. Furthermore, there is evidence that PET is more sensitive than CT for the evaluation of the response to neoadjuvant treatment, able in some cases to 'predict' pathologic response. Currently, there are no large series with regards to the initial locoregional staging of rectal tumors using PET and the significance of this method is mainly identified in neoadjuvant protocols (Heriot et al., 2004).

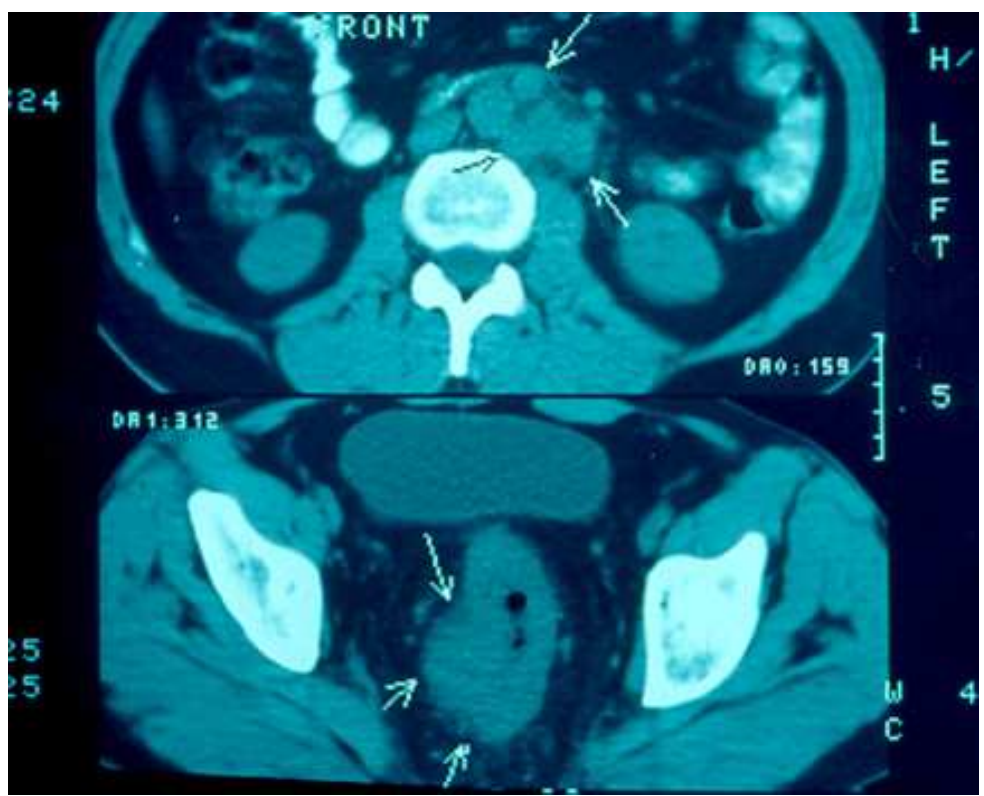

Fig. 1. Rectal mass identified on CT scan. Metastatic lymphnodes at the inferior mesenteric artery root. 


\section{Surgical approach to rectal cancer}

\section{Pramateftakis MG, Tsoulfas $G$}

After the diagnosis and staging of a rectal tumor, a decision needs to be made with regards to the optimal method of surgical treatment. To save or not to save the sphincters is a common question. Is there a level below which an anastomosis should not be attempted? The optimal surgical technique for low rectal tumors remains controversial in the absence of randomized trials. Conversely, too often, in a fanatic effort to avoid a colostomy and to reestablish intestinal continuity, surgeons compromise on the margins of resection. The consequences are often tragic for the patient (recurrence, anastomotic obstruction, functional problems and pelvic pain).

The intention of oncologic surgery for rectal cancer is the removal of the primary tumour and regional lymphatics and the prevention of tumour cell spillage. Controversy still exists about the extent of lymphadenectomy, the importance of the Turnbull's no touch technique, the optimal free distal margin and the irrigation of the rectal stump. Whether complete retroperitoneal clearance of all lymphatic tissue ("pre-aortic strip") offers advantage to survival rates is still doubtful. There are no randomised clinical trials supporting the value of extended lateral internal iliac lymph node excision. Moreover, there is a high incidence of urinary and sexual complications because of autonomic nerve damage (Pramateftakis et al., 2010).

In 1981, Heald introduced the concept of total excision of the mesorectal adipose and lymphatic tissue for middle and lower rectal carcinomas, namely the Total Mesorectal Excision (TME). Apart from the TME, oncologic resection involves the mobilization of the splenic flexure, high ligation of the inferior mesenteric artery (IMA) and the sharp dissection under direct vision of the mesorectal tissues to the level of the levators. The fascia propria of the mesorectum and the nerve plexus must be preserved intact, leaving a smooth mesorectal surface. The middle rectal vessels must be cauterized. With this technique, all the lymphatic tissue surrounding the rectum is removed. The specimen may contain the tumor tissue, its intraluminal extent, the metastatic infiltrated lymph nodes, vessels and nodules. TME is now considered to be the 'gold standard' approach for the middle and low rectal cancers (Heald, 1982, 1992).

Hospital patients' volume seems to have an impact on colostomy rates, postoperative mortality and overall survival. In a series of 7257 patients diagnosed with Stage I-III rectal cancer between 1994 and 1997, there were statistically significant differences in colostomy rates $(29.5 \%$ versus $36.6 \%)$, 30-day postoperative mortality $(1.6 \%$ versus $4.8 \%)$ and in overall 2-year survival $(83.7 \%$ versus $76.6 \%)$ in hospitals with higher patient volumes $(>20$ procedures per year) compared to those with fewer than 7 procedures annually. The ability for sphincter-sparing surgery is also affected by the hospital volume. In an adjuvant treatment trial of 1330 patients with Stage II or III rectal cancer, the rates of abdoperineal resections as opposed to low anterior resections were significantly higher in low-volume hospitals (46\% versus 32\%, respectively) (Meyerhardt et al., 2004).

The type of operation that can be offered to a patient with rectal cancer depends not only on tumour stage, but also on the location of the tumour in relation to the surgical anatomy. Surgical anatomy refers to the anatomic landmarks that determine resectability and sphincter preservation. The NCI consensus on rectal cancer recommended localizing the tumour relation to the anal verge, which is defined as starting at the intersphincteric groove. Another important landmark defining the upper limit of the anal canal is the anorectal ring. 
From the surgeon's perspective, the top of the anorectal ring is the lower limit of a distal resection margin. A large, full-thickness cancer needs to be located high enough above the top of the anorectal ring to allow for an adequate distal margin if sphincter preservation is contemplated. If the dissection is to be carried lower towards the dentate line, then the tumor must be confined to the mucosa, submucosa, and superficial layer of the internal sphincter (Bleday \& Garcia-Aguilar, 2007).

Quality surgery and adjuvant therapy have improved overall 5-year survival rates for colorectal cancer over the last decades. It is nowadays proven that a sphincter-sparing surgical approach does not sacrifice survival in selected patients when an adequate margin can be achieved (Bleday \& Garcia-Aguilar, 2007).

In summary, aim of the technique chosen is the regional disease control, the radical tumor resection (R0) and the preservation of the sphincter mechanism (whenever possible). Therefore, depending on the tumor location, the surgical choices are the low anterior resection, the intersphincteric resection, the transanal resection and the abdominoperineal resection. All approaches will be discussed in detail in the following paragraphs.

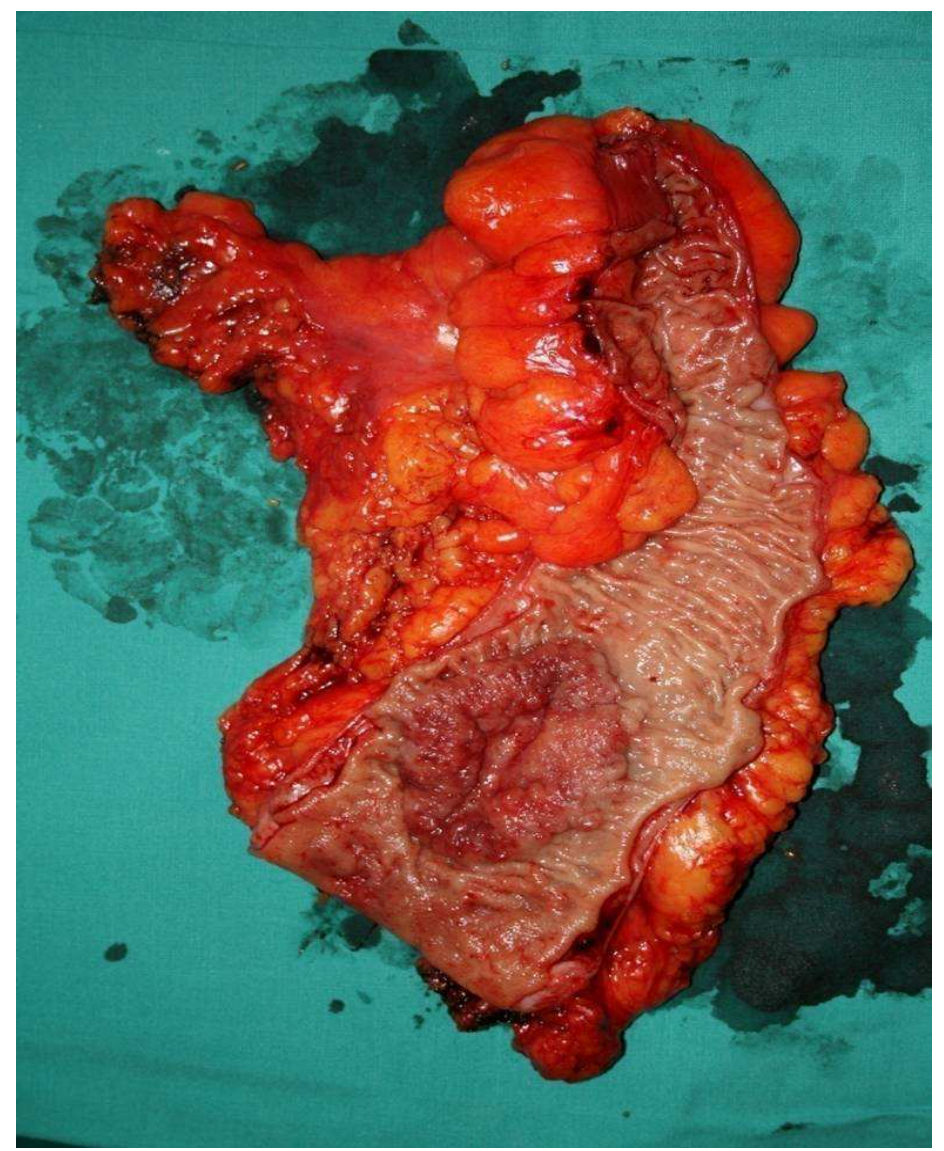

Fig. 2. Low anterior resection specimen with high ligation of the feeding vessels (IMA). 


\section{Low anterior resection for rectal cancer}

\section{Michalopoulos A, Papadopoulos V, Pramateftakis MG}

A low anterior resection is undertaken in order to remove malignant tumors of the middle and lower rectum. For the radical excision of a rectal cancer, a " $5-\mathrm{cm}$ rule" distal free margin below the tumor has been an important issue. However, intramural spread exceeds $1-2 \mathrm{~cm}$ in a few occasions only and further increase of the distal margin beyond $2 \mathrm{~cm}$ does not improve the locoregional recurrence rate or survival. An established principle is that the mesorectum and the wall of the rectum should be transected at the same level (Williams et al., 1983). The resection concerns the intra- and extraperitoneal rectosigmoid and the anastomosis is conducted below the peritoneal reflection ( $<8 \mathrm{~cm}$ from the anal ring). The anastomosis is performed either manually (usually in an end-to-end manner) or by the use of automatic stapling devices, in which case it can be performed as an end-to-end, end-toside or side-to-side anastomosis.

\subsection{Technical considerations \& controversies}

\subsubsection{Low anterior resection and coloanal anastomosis}

In case of a very low anterior resection, the anastomosis is performed at the level of the dentate line, after excision of the upper half of the internal sphincter. The direct end-to-end anastomosis is performed either transanally, or by the York Mason technique, the Kraske technique, or even by the use of a circular stapler. A diverting ileostomy should also be performed (Pramateftakis et al., 2010).

\subsubsection{Coloanal anastomosis with colonic J-pouch}

A colonic J-pouch is recommended for carcinomas of the middle and lower rectum, large benign tumors of the lower rectum, heavy radiation orthitis and rectal Crohn's disease.

Contraindications for a J-pouch include the infiltration of the levator muscles by the tumor, inflammation and fistulas of the perineum and anal incontinence.

The rectal cancer excision is similar to the traditional very low anterior resection, with the addition of a colonic J-pouch construction. The descending colon is preferred to the sigmoid colon, because it is firmer and has better adaptability. For the safety of the low anastomosis, the operation must be supplemented by the creation of a temporary ileostomy, which is usually reversed after 2-3 months. Patients with a pouch have fewer stool evacuations per day, but some of them may need enemas or suppositories to evacuate. However, the anastomosis is considered safer and there is a lower incidence of the post-operative low anterior resection syndrome, nevertheless only in the early postoperative period. During the late postoperative period, there are no statistically significant advantages of a colonic Jpouch when compared to the simple coloanal anastomosis, as the intestine gradually seems to adapt (Jeng-Kai et al, 2005; Nicholls, 1991).

\subsubsection{Low Colorectal anastomosis with ileocecal reservoir transposition}

An alternative method of a colonic reservoir after a low anterior resection is the ileocecal transfer, in cases of inadequate left colic flexure mobilization. The cecum, along with the final part of the ileum and their blood supply (ileocolic artery) are transferred to the rectal stump. In this case, the cecum is used as a pouch, with the added effect of a valve mechanism (ileocecal valve) (Jeng-Kai et al., 2005). 


\subsubsection{Pull-through (coloanal anastomosis)}

After removing the rectum, the anus is dilated and, using stay sutures to the rim of the rectal stump, the anus or the rectal stump is reversed and is delivered out of the anal ring, with the mucosa facing outwards. Then, through the inverted rectal stump, the sigmoid or the descending colon is pulled out for about $10 \mathrm{~cm}$ and the anastomosis is performed. Alternatively, a catheter can be placed into the sigmoid colon and the excessive intestine is excised 2 weeks later, after mucosal approximation with absorbable sutures (Bennett, 1986).

\subsubsection{Total Mesorectal Excision (TME)}

The posterior wall of the mesorectum is covered by the fascia propria, which is a part of the visceral fascia. The sacrum and the coccyx are covered by a strong aponeurotic fascia, which represents the continuation of Todd's fascia. The fascia of Waldayer is a thickening of this pelvic aponeurotic fascia and connects the rectal fascia to the pelvic sacral fascia. In the middle of the anterior wall, the rectum receives a reflection from the peritoneum of the posterior wall of the bladder in men or the uterus in women, creating the Douglas pouch, at a distance of 7-9 cm from the anus. This is usually deeper in women and divides the rectum in an intraperitoneal, covered by serosa in the front and sides and an extraperitoneal part, not covered by serosa, but by a thin layer of the visceral fascia, called Denonvillier's fascia (Heald, 1982).

The rectum is devoid of mesentery, but the fascia propria covers the lymphatic tissue and the lymphnodes of the rectum, the upper and mid rectal vessels, and lipoid tissue forming the "Mesorectum". The resection of the rectum and mesorectum with the lymph nodes and the preservation of the neural plexus is called a "total mesorectal excision" (TME). A correctly performed TME avoids complications from the urogenital system and the sphincters, since it does not damage the autonomic nerve plexus. Key step of the procedure is the identification and preservation of the pre-aortic superior sympathetic hypogastric plexus and the laterally located hypogastric nerves and sacral splanchnic nerves, forming the inferior hypogastric plexus (sympathetic-parasympathetic nerves S2-S4) on both sides of the pelvic wall. Intact nerves should look like a "fishbone" near the sacral promontory, after a proper dissection (Miles, 1971).

TME is currently recommended for distal mid- and lower rectal cancers, with complete excision of the visceral mesorectal tissue, down to the level of the levators. For upper third or rectosigmoid cancers a tumour specific mesorectal excision (TSME) should be preferred, performing perpendicular and circumferential excision of the mesorectum to a resection margin level of $5 \mathrm{~cm}$ distal to the tumour (Wibe et al., 2002).

\subsubsection{Extent of distal resection margin for rectal cancer}

Even though the intraluminal spread of colorectal cancer is accomplished through the lymphatics of the submucosa or those of the perirectal fat, the mucosal cancer spread rarely extends beyond the $4 \mathrm{~cm}$, distally. In well differentiated, very low carcinomas a distal margin of $2 \mathrm{~cm}$ is considered satisfactory, since the $98 \%$ of tumour dispersion is in a distance less than $2 \mathrm{~cm}$. This necessitates the preoperative identification of the degree of tumor cell differentiation and the proper measurement of the distal margin in the fresh specimen by the surgeon (Heald, 1982; Wibe et al., 2002). 


\subsubsection{High ligation of the inferior mesenteric artery (IMA)}

High ligation of the inferior mesenteric artery is mandatory. The dissection and ligation of the IMA $1 \mathrm{~cm}$ from the aorta, preserves the superior hypogastric plexus, formed by fibres of the sympathetic ganglia of the prevertebral sympathetic chain. In a study by Hohenberger et al, 14 patients with local recurrence after 'radical excision' of rectal carcinomas underwent a selective angiography of the inferior mesenteric artery. The remaining stamp of the IMA was found to be longer than $1 \mathrm{~cm}$ in 11 cases $(79 \%)$. Some authors report a 5-year survival improvement by $5,7 \%$ following a high IMA ligation, while others found no improvement in survival even in patients of stage Dukes C (Hohenberger et al., 1991).

\subsubsection{Extensive lymphatic clearance}

Extensive lymphatic dissection includes the excision of tissues and lymph nodes surrounding the aorta and iliac vessels reaching proximally to the duodenum, distally to the levator muscles and laterally to the ureters. It also includes the TME, the dissection of the thyroid spaces and the possible ligation of one of the internal iliac vessels. Even though 5year survival is reported to increase from $2.3 \%$ to $10.4 \%$ after extensive lymph node dissection, this approach is accompanied by higher morbidity and increased risk of complications, such as damage to the ureters and cystic or sexual dysfunction (McDermott et al, 1982).

\subsubsection{No-Touch Technique}

This technique involves the early ligation of the inferior mesenteric vessels (first the inferior mesenteric vein distally to the lower border of the pancreas followed by the inferior mesenteric artery, flat to the aorta), before any handling of the tumor finds place. Following the vessel ligation, the colonic lumen is isolated proximally and distally to the cancer. In this way, the spillage of cancer cells during the operating manoeuvres is avoided.

Particularly for the rectal carcinoma, the intraluminal cancer cells apoptosis, spillage and implantation of tumour cells are considered to be important for the increase of the cancer relapses across the stapled line, following a low anterior excision. The technique of early luminal occlusion with a clamp or a rectal stapler distally, followed by complete TME and the intrarectal wash out with antiseptics and cytotoxic solutions, appears to reduce the local recurrences (Young-Fadok et al., 1998). However, in a randomized, prospective study by Wiggers et al., there was no significant difference in the 5-year survival rate between the two techniques (Wiggers et al., 1988).

\subsubsection{Oophorectomy}

The incidence of synchronous metastases to the ovaries in case of colon cancer is $2-8 \%$. Colorectal carcinomas metastasize to the ovaries either by direct implantation or by lymphatic and haematogenous metastases, due to the pelvic lymphatics. Ovarian metastases seem to appear more frequently in postmenopausal women, while at the same time the risk of developing primary ovarian malignancy is referred to be 5 times higher when compared to the general population. However, prophylactic oophorectomy does not appear to offer any benefits to all colorectal cancer patients, because the risk of occult microscopic disease seems to be low (Young-Fadok et al., 1998). Bilateral oophorectomy is advised when one or both ovaries are grossly abnormal or involved with contiguous extension over the colon cancer. However, prophylactic oophorectomy is not recommended. (Level of Evidence Class II, Grade B) (Otchy et al., 2004). 


\subsection{Early complications following low anterior resection \\ 4.2.1 Bleeding}

Intraoperative bleeding is usually due to inadequate preparation of the rectal stump, an error in the performance of the purse string suture, poor haemostasis of the mesorectum, inadequate vascular ligations or a presacral plexus injury. Endo-rectal bleeding is considered to be due to the shape of the clips, forming a " $\mathrm{B}$ " after their closure and allowing gaps through which bleeding can occur. Bleeding may also be due to the capture of foreign tissue inside the circular stapler, such as the prostate and the vagina (Nesbakken et al., 2002).

\subsubsection{Anastomotic leakage}

Anastomotic dehiscence occurs more commonly in rectal and oesophageal anastomoses than in other parts of the alimentary tract. The main reasons are technical difficulties in dissection of these organs and their easily compromised blood supply. Leakage following a low anterior resection can cause a faecal fistula, pelvic peritonitis or generalized peritonitis. Subclinical leaks are often reported when a postoperative radiologic control is conducted (Kanellos I et al., 2004).

Systematic protective colostomy or ileostomy does not prevent the occurrence of the complication, but limits its consequences, as well as the postoperative hospitalization time. Elderly patients may develop delayed leakages, due to slower healing capabilities (Bittorf et al., 2003; Demetriades et al., 2004).

Anastomoses located 3 to $6 \mathrm{~cm}$ from the anal verge may lead to leak rates up to $17 \%$. Some centres are now routinely fashioning a 'protective' diverting stoma. In a randomized multicentre trial, the overall rate of symptomatic leakage was reported to be $19.2 \%$. Patients who had a defunctioning stoma had an anastomotic leakage at $10.3 \%$ of the cases and those without a stoma had leakage rates of $28 \%(p \leq 0.001)$. The necessity for an urgent reoperation was $8.6 \%$ in patients with a protective stoma and $25.4 \%$ in those without one ( $\mathrm{p} \leq 0.001$ ) (Matthiesen et al., 2007; Vrakas et al., 2010).

In another study comparing laparoscopic vs open TME, intestinal obstruction occurred in 5 cases in the laparoscopic group and in 3 cases in the open group. In the laparoscopic group, intestinal obstruction was in the majority of the cases $(60 \%)$ caused by a problem at the ileostomy site. As a consequence, the loop ileostomy was abandoned as a mode of diversion in favour of the use of a loop transverse colostomy (Staudacher et al., 2007).

Whether a loop ileostomy or a loop colostomy is a better form of faecal diversion remains controversial. Two randomized studies that compare the two techniques and included only patients who had elective TME for rectal cancer reported controversial results. Nevertheless, a trend towards a higher anastomotic leak rate has been observed in patients in whom a stoma was not fashioned at the primary operation. Therefore, many surgeons who perform TME have now the policy to temporarily defunction almost all low anastomoses (Law et al., 2002; Rullier et al., 2003; Staudacher et al., 2007).

Subclinical (meaning non-symptomatic) anastomotic failure may occur in up to $51 \%$ of patients, associated with mortality rates ranging from $6 \%$ to $22 \%$. Branagan \& Finnis reported a 30-day mortality rate of $10 \%$ (Branagan \& Finnis, 2005). Ptok et al found that patients with anastomotic leakage had a higher rate of immediate postoperative complications ( $50.8 \%$ vs $26.5 \%, \mathrm{p} \leq 0.001$ ) and longer hospital stay (29 vs 15 days, $\mathrm{p} \leq 0.001$ ) (Ptok et al., 2007). Taflampas et al reported that male sex, smoking, alcohol abuse and preoperative malnutrition are all risk factors for anastomotic leakage. They also concluded 
that the distance of the anastomosis from the anal verge has a significant impact on anastomotic failure rates. They recommend the routine mobilisation of the splenic flexure and anastomosis of the descending colon, instead of the sigmoid, to the rectal stump (Taflampas et al., 2009).

The use of a colonic J-pouch seems to decrease the leakage rates after low anterior resection. The size and stage of the primary tumor, the type of the anastomosis (stapled or handsewn), omentoplasty, extraperitoneal positioning of the anastomosis, bowel preparation, the use of laparoscopy and the use of a pelvic drain do not reduce the leakage rates. The short scheme of radiotherapy is also not considered to be a significant risk factor. Collagen type and enzyme expression of the tissues, blood transfusions and the learning curve associated with the use of staplers are factors whose association and importance on anastomotic leakage is not yet clarified (Taflampas et al., 2009).

It is uncertain whether the long scheme of radiotherapy or the addition of chemotherapy increases the anastomotic leakage rate. The value of creating a protective stoma is debatable. It may be indicated for anastomoses lower than $6 \mathrm{~cm}$ from the anal verge, even though some suggest its elective use (Taflampas et al., 2009).

\subsection{Late complications following low anterior resection \\ 4.3.1 Anastomotic stricture}

A stricture of the anastomosis is defined as the difficulty of passing the $19 \mathrm{~mm}$ rectoscope through it. Possible reasons considered are reactive fibrosis to a foreign body (clips), or the consequence of a subclinical leakage. The first possibility is unlikely, while the latter is in contrast to the fact that since there are statistically more subclinical leakages in hand sewn coloanal anastomoses, they should therefore display more frequently strictures than the stapled ones; something that does not happen.

Other causes of strictures are ischemia caused by excessive devascularisation of the rectal stump and the use of small calibre staples $(<28 \mathrm{~mm})$. Defunctioning colostomies are also thought to provoke strictures because of regression in the diameter of the distal colon (Rees et al., 2004).

\subsubsection{Rectovaginal fistula}

Rectovaginal fistulae may be a consequence of radiation therapy preceding or following rectal surgery, of inflammatory bowel diseases, such as ulcerative colitis and especially Crohn's disease, or as a complication following improper firing of the stapler. When creating a stapled anastomosis, the accidental capture of vaginal wall between the main body and the anvil of the stapler results in the creation of a rectovaginal fistula. Other causes for fistula creation are subclinical anastomotic dehiscence, haematoma, ischemia, or abscess. Incomplete or excessive rectal stump devascularisation can also lead to a rectovaginal fistula formation.

In cases of a fistula because of cancer recurrence, a lower anterior resection, or an abdominoperineal resection must be performed.

In other cases, a diverting colostomy may initially be conducted followed by a restorative operation at a later stage (transvaginal or transanal). Adhesive substances for eliminating the fistula have also been tried, with controversial results (Sugarbaker, 1996).

\subsubsection{Urinary and sexual dysfunction}

Postoperative impotence and/or retrograde ejaculation have been observed in $25 \%-75 \%$ of cases, particularly when lateral wall lymphadenectomy and splanchnic nerve resection are 
performed. In contrary, when TME with careful nerve-sparing dissection is performed, impotence occurs in only $10 \%-29 \%$ of cases (Bleday, 2007). Nevertheless, excessive dissection during TME may also lead to sexual dysfunction. During the dissection of the rectum inside the pelvis, the so called "lateral ligaments" should not be clamped and ligated, but cauterized instead. These ligaments contain small nerve branches of the inferior hypogastric plexus and minor vessels arising from the branches of the internal iliac artery, which pass to the mesorectum. These plexuses can be damaged by dissection and clamping. Great care also has to be taken during the lateral dissection of the Denonvillier's fascia, where the neurovascular bundle of Walsh rises from the inferior hypogastric plexus. That bundle runs along the posterolateral aspect of the prostate.

The clinical consequence of an isolated sympathetic nerve injury is retrograde ejaculation. Dissection beneath the presacral or pelvic fascia from the sacral promontory around to the lateral pelvic sidewall can injure both parasympathetic and sympathetic nerve fibres which can result in impotence and bladder dysfunction (Nesbakken et al., 2002).

\subsubsection{Incontinence}

It may be due to a disorder in the sensation for faecal evacuation (due to the rectal excision), damage to the pudendal nerves, destruction of nerve plexuses or damage to the sphincter mechanism (Bittorf et al., 2003; Rasmussen et al., 2003).

\subsubsection{Post-operative low anterior resection syndrome}

The low anterior resection syndrome characterizes the disturbance in the perception of continence of various degrees, the quality and frequency of evacuation, urgency, tenesmus, urinary and sexual dysfunction following a low anterior resection of the rectosigmoid. Continence, as well as normal bowel evacuation, is due to the integrity of sensory, motor and central nervous functions and anatomic formations (hypogastric plexuses, pudendal nerves, tension receptors of the pelvic floor etc.) Furthermore, the knowledge and acceptance of the coordination mechanism of continence and defecation (constipation, incontinence, continence and biofeedback and re-education) plays an important role.

Incontinence is due to:

a. Disorders of the rectal reservoir, eg. because of chronic inflammation (Crohn's disease, ulcerative colitis, radiation) or because of a very low anterior resection

b. Neurologic disorders, eg. damage of the CNS (CNS or spine injury), sensory receptor damage (Whitehead operation, pull-through excision) or damage to the motor transmission (perineal descent syndrome, age, childbirth)

c. Muscle damage, eg. due to sphincteric lesions (fistulas, episiotomy, accidents)

d. The low anterior resection syndrome (Rasmussen et al., 2003; Matzel et al., 2003)

Theories that have been reported to be associated with the low anterior resection syndrome are:

i. Theory of loss of the rectal pouch.

ii. Theory of loss of anal sensation.

iii. Theory of damage to the internal anal sphincter.

iv. Theory of the proximal intestine's lumen diameter (Lumen score, $\mathrm{r}^{2}$ ).

v. Theory of sympathetic denervation (Rasmussen et al., 2003).

The Low Anterior Resection Syndrome is a multi-factorial condition (sympathetic denervation, rectal pouch capacity loss, sphincteric damage, colonic motility disorders and 
patient's psychopathology). Improvement is expected at 6 months after the operation, while the CNS may act unpredictably. The J-pouch construction is controversial and chemoradiotherapy increases the degree of incontinence. Prognostic factors for the possibility of occurrence of post-operative incontinence are anal sensitivity testing, manometry, radiologic data and anorectal endosonography. However, the preservation of the nervic plexuses may contribute in minimizing the consequences of the Low Anterior Resection Syndrome. Low anterior resection may cause some degree of incontinence in $15-30 \%$, but regardless of that, $70 \%$ of the patients are fully and $14 \%$ partially satisfied, post-operatively (Matzel et al., 2003; Rasmussen et al., 2003).

\subsection{Local recurrence and survival after low anterior resection; the importance of TME}

Total mesorectal excision rapidly became the "gold standard" for anterior resection of the rectum and a marked reduction of local recurrence rates has been seen. It is reported that the locoregional recurrence rate at 4 years by conventional techniques is $12-32 \%$, in contrast to 69\% following TME (Wibe et al., 2002).

Data from a randomized, prospective trial by the National Surgical Adjuvant Breast and Bowel Project, demonstrated no significant differences in survival or local recurrence when comparing distal rectal margins of $<2 \mathrm{~cm}, 2-2.9 \mathrm{~cm}$ and $>3 \mathrm{~cm}$ (Heriot et al., 2006; Saito et al., 2009). As a result, a 2-cm distal margin is considered acceptable for resection of rectal carcinoma; even though a 5-cm proximal margin is still recommended for upper rectal cancers. The radial margin seems to be critical for local control. Macroscopic pathologic characteristics of completeness of mesorectal excision are (Vordermark et al., 1989):

Incomplete excision: Little bulk to the mesorectum

Defects in the mesorectum up to the muscularis propria

Very irregular circumferential margin at transverse sectioning

Nearly complete excision: Moderate bulk to the mesorectum

Irregularity of the mesorectal surface with defects greater than 5 $\mathrm{mm}$, but not up to the muscularis propria

No area of visibility of the muscularis propria

Complete excision:

Intact bulk to the mesorectum with a smooth surface

Only minor irregularities of mesorectal surface

No surface defects greater than $5 \mathrm{~mm}$ in depth

No 'coning' of the distal mesorectum

Smooth circumferential margin at transverse sectioning

Local recurrence may result from an incomplete radial or circumferential margin. About $25 \%$ of cases may have unsuspected involvement of the radial margin after rectal excision, which may result in local recurrence from an incomplete radial resection rather than from an incomplete distal mesorectal excision. A positive circumferential (radial or lateral) margin increases the risk of local recurrence 3.5 times and doubles the risk of disease-related death. Completeness of the mesorectum in the specimen predicts both local recurrence and distant metastases. The mesorectal surface must be marked with ink before formalin fixation. Assessment of the distance between the tumor and the nearest radial margin is mandatory. Circumferential margin is scored as positive if the tumour is located $1 \mathrm{~mm}$ or less from the inked non-peritonealised surface of the specimen (Compton et al., 2000; Wibe et al., 2002).

The distance of the tumour from the proximal and distal margins should also be assessed in millimetres. Anastomotic recurrences are rare when this distance is $\geq 5 \mathrm{~cm}$. For a lower rectal cancer, a $2 \mathrm{~cm}$ margin is considered adequate (Compton et al., 2000). 
The R-classification indicates the completeness of a surgical excision, depending to a large part on the radial margin. R0 suggests complete tumor resection with all margins negative, $\mathrm{R} 1$ is an incomplete tumor resection with microscopic margin involvement and R2 is an incomplete tumor resection with macroscopic involvement of a margin and gross residual tumor.

Total mesorectal excision may reduce local recurrence rates from $20-30 \%$ to $8-10 \%$ or less, and may increase 5 -year survival rates from $48 \%$ to $68 \%$. There is strong evidence that sharp dissection under full visualisation is superior to a blunt and partly blind dissection technique and that one should avoid entering into the wrong dissection plane, keeping the fascial envelope intact (Compton et al., 2000).

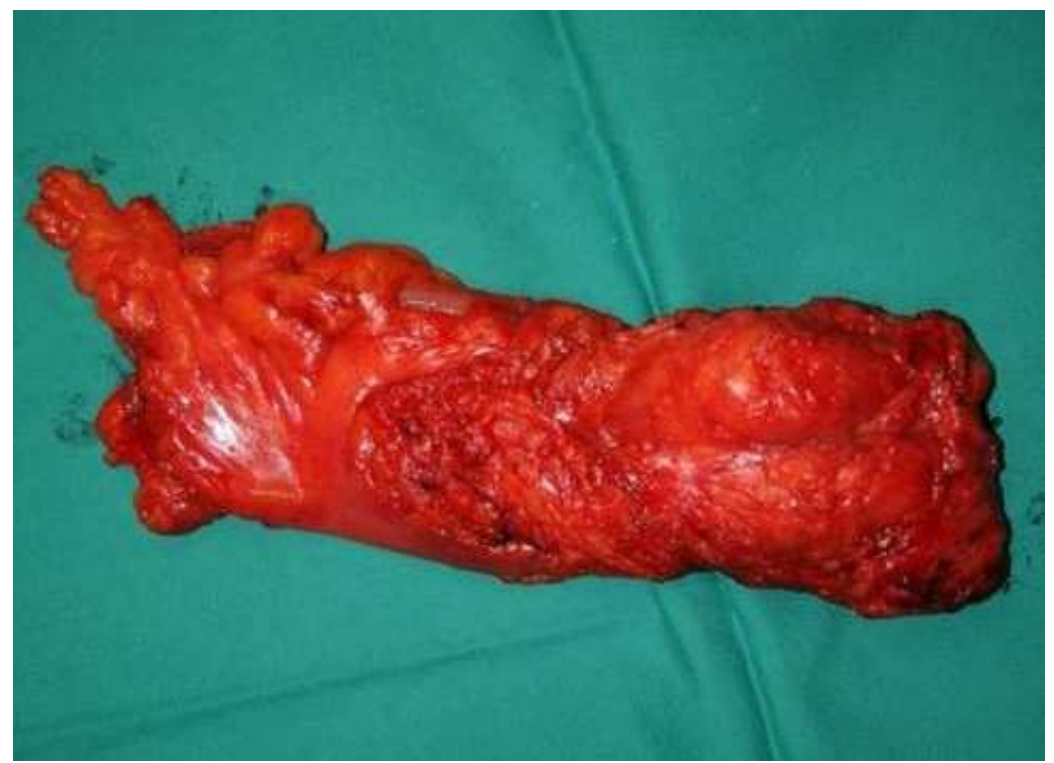

Fig. 3. TME on rectal resection specimen.

\section{Intersphincteric resection for rectal cancer}

Spanos K, Pramateftakis MG, Tepetes K

For technical and oncological reasons, the standard surgical treatment in very low rectal cancers is the abdominoperineal resection. Nevertheless, in recent years, intersphincteric resection (ISR) has been proposed to offer sphincter preservation in patients with such low lesions (Chamlou et al., 2007).

The principle of the ISR technique is based on an anatomic dissection plane between the internal anal sphincter (IAS) and the external anal sphincter (EAS). The technique incorporates a combined abdominal and perineal approach. During ISR, a transanal division of the rectum, with removal of part or the entire IAS is performed after TME, thus obtaining an adequate distal margin. Restoration of bowel continuity is achieved by performing a hand-sewn coloanal anastomosis. For tumors less than $3 \mathrm{~cm}$ from the dentate line, an ISR may be performed (Chamlou et al., 2007). 


\subsection{Indications}

Inclusion criteria for performance of ISR include the following:

- $\quad$ Local spread restricted to the rectal wall or the IAS.

- Adequate sphincter function and continence.

- Absence of distant metastases.

- $\quad$ Distal margin potential of $2 \mathrm{~cm}$ for T2, T3 tumors.

- $\quad$ Distal margin potential of $1 \mathrm{~cm}$ for T1 tumors

Contraindications to the performance of ISR are the presence of fecal incontinence, T4 lesions, undifferentiated tumors, as well as tumors invading the puborectalis and the EAS.

The extent of local disease can be assessed with the use of MRI and/or endorectal ultrasound. Such studies greatly assist in selecting patients for performance of ISR. Patients with T1 and T2 lesions usually undergo ISR alone. For patients with T3 tumors and T2 tumors with IAS infiltration, neo-adjuvant radio-chemotherapy is recommended (Rullier et al., 2005; Yamada et al., 2009).

\subsection{Short-term adverse events}

The overall operative mortality associated with ISR is $1.6 \%$ and the anastomotic leak rate $10.5 \%$ (range $0-48 \%$ ). Anastomotic stricture is reported at $5.8 \%$.

Rates of clinically apparent anastomotic leakage following stapled anastomosis after anterior resection are in the range of 3-15\%. Leakage rates rise significantly for more distally sited anastomoses. Anastomotic leakage is associated with postoperative anastomotic stricture, cancer recurrence, poor postoperative function as well as increased operative mortality. ISR can be performed with acceptable rates of anastomotic leakage and low operative mortality (Rullier et al., 1998; Tilney \& Tekkis, 2007).

\subsection{Oncologic outcomes}

Radical surgical removal of the tumor is the only chance for permanent cure of rectal cancer, despite all progress in the development of oncologic therapy. Rullier et al reported a local recurrence rate of $2 \%$ in their series of 92 patients undergoing ISR (Rullier et al., 2005). Most patients $(78 \%)$ had T3 lesions and $88 \%$ underwent long-course neo-adjuvant radiochemotherapy. The overall 5-year survival rate was $81 \%$, with a 5 -year disease-free survival of $70 \%$.

Yamada et al reported a similarly low 2.5\% cumulative 5-year local recurrence rate, a 5-year disease-free survival rate of $83.5 \%$ for stage II patients and $72 \%$ for stage III patients (Yamada et al., 2009).

Tilney and Tekkis performed a literature search to identify studies reporting outcomes following ISR. Twenty-one studies accumulating a total of 612 patients were identified (Tilney \& Tekkis, 2007). The pooled rate of local recurrence was $9.5 \%$ with an average 5 -year survival of $81.5 \%$. Distant metastases occured in $9.3 \%$.

Rates of local recurrence following low anterior resection for the treatment of rectal cancer are commonly reported in the range of $2.6-32 \%$ following surgery alone (Heriot et al., 2006). Preoperative chemoradiation therapy has led to local recurrence rates in the $6 \%$ range.

Therefore, the performance of ISR for the treatment of very low rectal cancer affords similar oncologic outcomes to those of conventional resections. Moreover, Saito compared outcomes of patients undergoing ISR with patients undergoing abdoperineal resection (APR). Similar local recurrence rates (ISR=10.6\%, APR=15.7\%, $\mathrm{p}=$ non-significant), and 5- 
year disease-free survival (ISR=69.1\%, APR=63.3\%, p=non-significant) were reported (Saito et al., 2009). Patients undergoing ISR had significantly longer 5-year overall survival compared to patients undergoing APR (ISR $=80 \%, A P R=61.5 \%, p<0.05$ ). As a conclusion, local and distant oncologic outcomes are not compromised with ISR. It is considered that the risk of local recurrence is more likely due to circumferential margin involvement than to distal margin involvement.

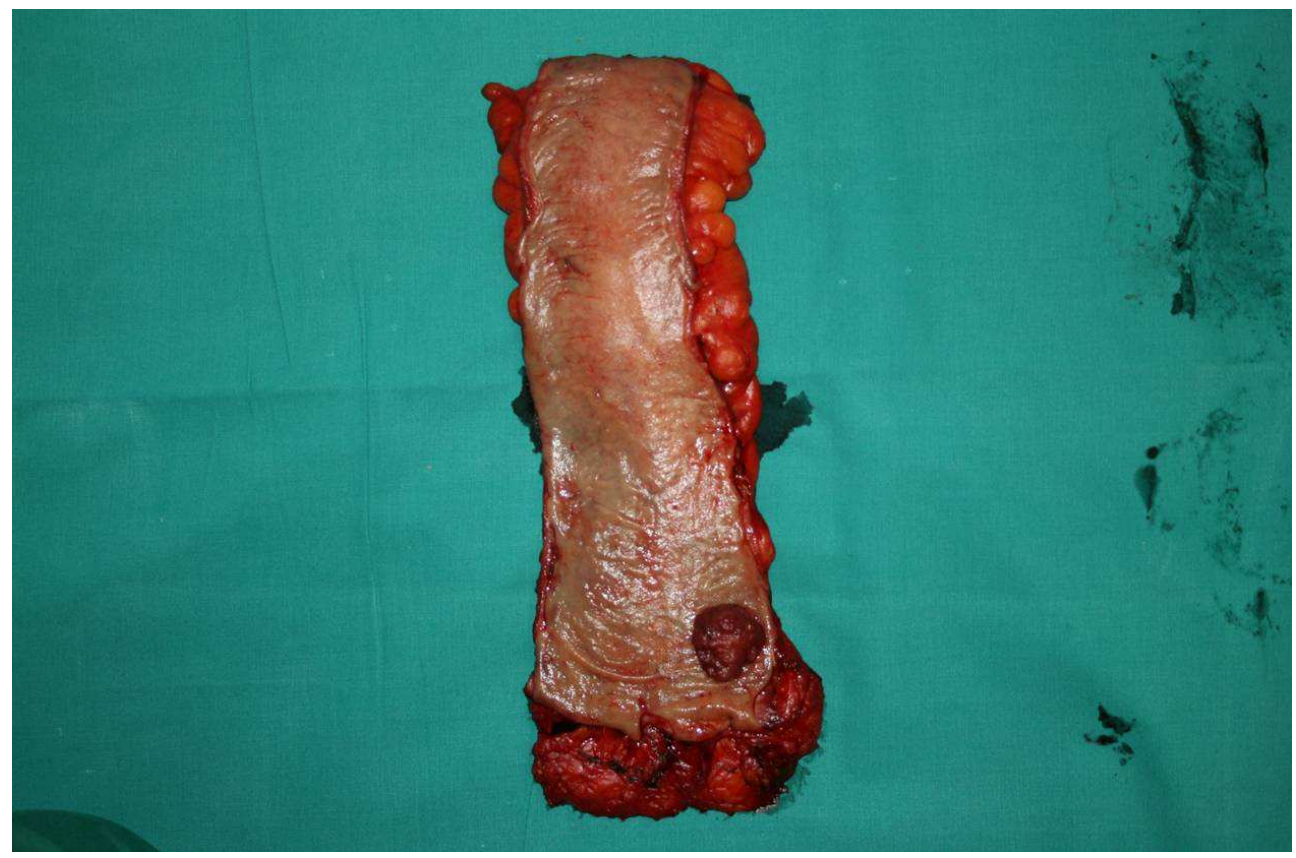

Fig. 4. Intersphincteric resection of low rectal cancer.

Risk factors for local and distant recurrence after ISR were reported by Akasu et al. Local recurrence rate was $6.7 \%$ and distant recurrence was $13 \%$ (Akasu et al., 2008). In the multivariate analysis, risk factors for local recurrence included positive microscopic resection margins, focal differentiation of tumor (tumor budding) and elevated preoperative levels of CA 19-9 (> $37 \mathrm{U} / \mathrm{ml}$ ). The identified risk factors for distant recurrence were pN1 \& $\mathrm{pN} 2$ disease, poor differentiation and the distance of tumor from the anal verge $(2.5 \mathrm{~cm})$.

\subsection{Anorectal physiology}

An important goal of sphincter-preserving surgery is to reach acceptable quality of life levels by preserving fecal continence. The main concern of the ISR technique is functional outcome. Physiologic studies have shown that the anal resting pressure is $55 \%$ due to the IAS, 15\% due the hemorrhoidal plexus and 30\% due to the EAS (Sangwan \& Sola, 1998).

Total or partial excision of the IAS is bound to affect continence. Furthermore, preoperative radiation therapy may cause additional loss of sphincter function. Kohler et al reported a 29\% reduction in resting anal pressure following ISR. Squeeze pressure recovered to preoperative levels after 12 months. Rullier et al compared outcomes in patients undergoing partial or 
subtotal IAS resection. Subtotal excision of the sphincter was associated with significant reduction in resting but not squeeze pressure after ISR (Kohler et al., 2000; Rullier et al., 1999).

\subsection{Functional outcomes and quality of life}

Bretagnol et al reported that faecal continence measured by both the Kirwan and Wexner scores was significantly worse after ISR. In addition, the need for anti-diarrheal medication was higher in patients undergoing ISR compared with patients which had undergone conventional coloanal anastomosis (Bretagnol et al., 2004).

Functional and continence score results were similar between patients undergoing partial ISR and total ISR. Frequency, urgency, the Wexner score and the Fecal Incontinence Severity Index (FISI) were shown to be significantly improved following colonic J-pouch reconstruction compared with straight coloanal anastomosis.

Regarding quality of life (QOL), Bretagnol et al used both the SF-36 and the Fecal Incontinence Quality of Life (FIQL) to compare QOL between patients undergoing ISR and conventional coloanal anastomosis. There was no difference in the QOL scores between ISR patients and conventional coloanal anastomosis patients in the physical and mental subscales of the SF-36.

Patients undergoing ISR with J-pouch reconstruction scored better in the domains of lifestyle, coping, depression and embarrassment at 3 months postoperatively but worse in the domain of embarrassment at the first postoperative year (Bretagnol et al., 2004).

\section{Local excision for rectal cancer}

Tepetes K, Pramateftakis MG, Spanos K

Local excision (LE) seems to be an attractive therapeutic option because of the minor morbidity, short recovery time and excellent postoperative functional results. There is, however, a significant issue regarding the long term oncological results because of the limited ability of the technique in controlling regional disease.

\subsection{Indications}

The ideal candidates for LE should theoretically be:

1. Low risk $\mathrm{T} 1, \mathrm{~T} 2$ tumors

2. Patients with significant co-morbidities unable to undergo a radical procedure

3. Symptomatic patients with multi-organ distant metastatic disease

4. Well informed patients denying a radical procedure or a stoma

Generally, three approaches to local excision are reported: a) the transanal (conventional or Transanal Endoscopic Microsurgery), b) the transcoccygeal, and c) the transsphincteric. The transanal techniques have been customized for a long time throughout the world and for this reason they can be evaluated more reliably (Garcia-Aguilar et al., 2000).

Factors associated with either the efficacy or the safety of the transanal excisions are the macroscopic and microscopic characteristics of the lesions.

i. Macroscopic characteristics:

1. T1, T2 lesions

2. Lesions located within the distal $10-11 \mathrm{~cm}$ of the rectum

3. Lesions smaller than $4 \mathrm{~cm}$

4. Lesions involving less than $40 \%$ of the lumen circumference. 
ii. Microscopic characteristics:

1. Tumor invasion (T): The local recurrence rate is strongly related to the depth of the initial mural invasion (T stage). It is not only the size of the tumor per se that makes the difference, but the lymph node involvement ( $\mathrm{N}$ stage) as well, which is independently associated. T1 tumors have a $6-12 \%$ incidence of lymph node (LN) involvement, T2 tumors have positive lymph nodes (LNs) in $17-22 \%$ of the cases and T3 tumors have LN involvement in more than $66 \%$ of the cases. The aforementioned differences are reported to result in different 5-year local recurrence rates, namely $5 \%$ for $\mathrm{T} 1$ tumors, $18 \%$ for $\mathrm{T} 2$ tumors and $22-33 \%$ for $\mathrm{T} 3$ tumors (Bouvet et al., 1999).

2. Lymph node involvement $(\mathrm{N})$ : The $\mathrm{LN}$ involvement is not only associated with the $\mathrm{T}$ stage. Well or moderately differentiated T1 and T2 lesions may present with positive LNs in $14 \%$ of the cases and they may have a 5-year local recurrence rate of $11 \%$, whereas poorly differentiated same size tumors have positive LNs in $30 \%$ of the cases and a 5-year local recurrence rate of 33\%. In addition, T1 and T2 tumors without vascular, lymphatic or perineural infiltration present positive LN stages in $4-17 \%$, in comparison with same size lesions with vascular, lymphatic of perineural infiltration which have LN positive disease in $31-33 \%$ of the cases. Finally, it is reported that mucinous rectal cancers have positive LN stage in $52 \%$ of the cases, in comparison with the non-mucinous tumors which have LN positive stage in $30 \%$ of the cases (Bayar et al., 2002).

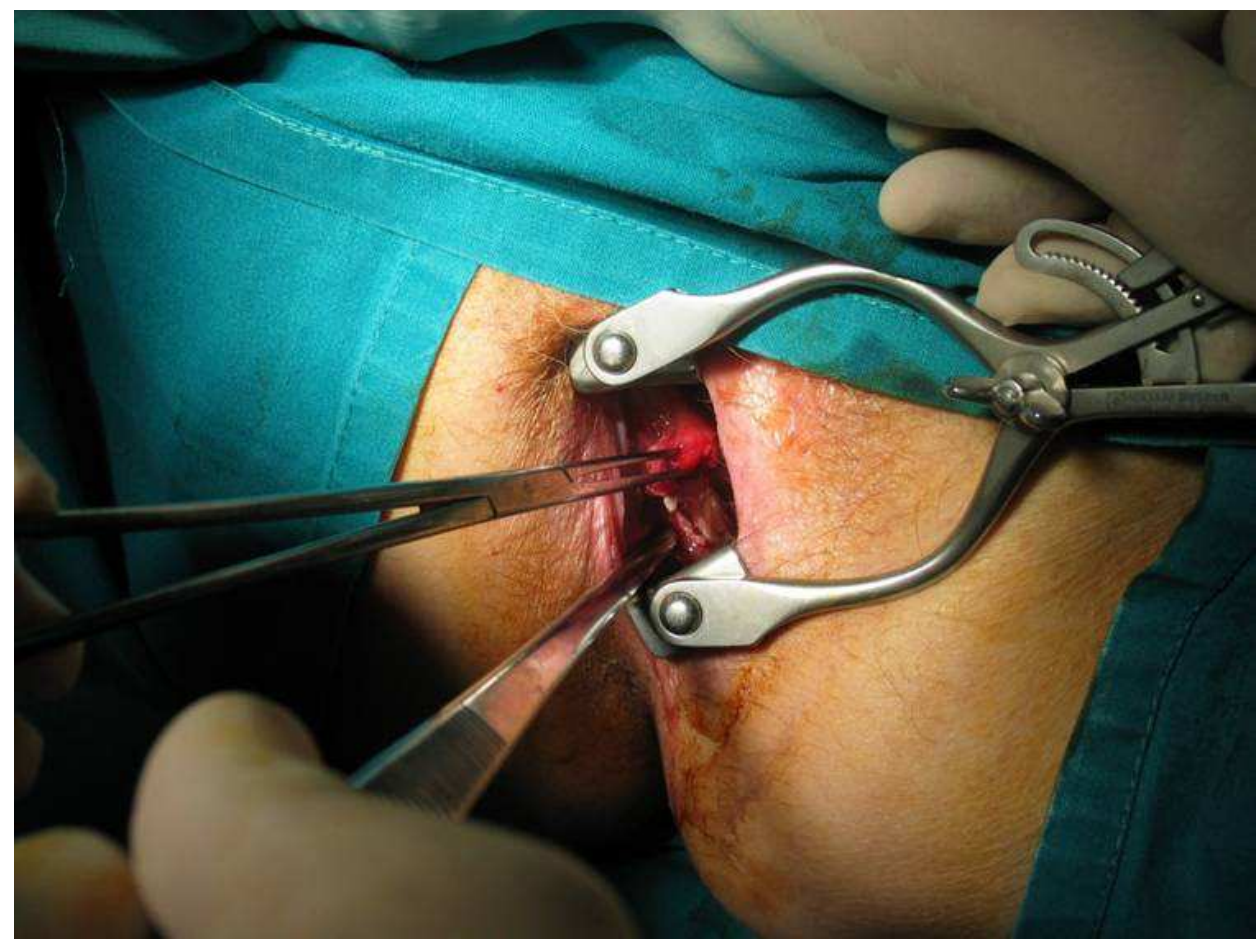

Fig. 5. Transanal excision of T1 lesion of the lower rectum. 


\subsection{Recurrence \& survival}

Local transanal excision of early rectal cancers (T1, T2) can be of value in well-informed patients. The locoregional recurrence rate for $\mathrm{T} 1$ tumors ranges from $4 \%$ to $29 \%$ and the 5year survival rate ranges from $83 \%$ to $100 \%$. The best results are reported to be achieved in well-differentiated, non-mucinous, non-ulcerative lesions without vascular, lymphatic or perineural invasion and negative $\mathrm{N}$ staging. Quite often though, there are discrepancies in reported patient series with regards to patient selection criteria, staging protocols, surgical techniques, adjuvant treatment or length of follow-up. The length of follow-up is of paramount importance, especially in old patients carrying high co-morbidity. In addition, tumor recurrence can be seen later than 5 years postoperatively and $28 \%$ of rectal cancer deaths occur later than this time interval. Thus, 10-year survival following local excision for $\mathrm{T} 1$ and $\mathrm{T} 2$ tumors drops to $74 \%$ and $72 \%$ respectively and the 10 -year local recurrence rate is $17 \%$ to $26 \%$ (Chen et al., 2005; Garcia-Aguilar et al., 2000).

There are no randomized trials comparing radical surgery (RS) to local excision, but there are comparative data from retrospective studies originated in specialized centres with regards to $\mathrm{T} 1$ rectal cancers. In these reports, recurrence rates following LE are 2-fold to 5fold higher. The cancer related survival rates of LE are also inferior to those of RS. The differences however are less prominent compared to those regarding recurrence, probably due to the short life expectancy of the older patients undergoing more often LE or ablative techniques. Another cause of discrepancy between groups is the proportion of patients undergoing salvage surgery in case of local recurrence. This rate varies significantly $(50 \%$ to $80 \%$ ) and the 5-year survival rates present a similarly wide range (30\% to $88 \%$ ). The long term results in these cases are poorer than those following initial RS. More than $50 \%$ of salvage surgery cases require extended pelvic dissection due to the size and the extent of recurrent disease. Thus, 6-year survival rate is reported to be $30 \%$ compared with the average 5-year survival which is over $50 \%$. Generally, it seems that less than $25 \%$ of patients who develop recurrence following LE are eventually cured (Endreseth et al., 2005; Mellegren et al., 2000).

There is however a group of patients undergoing LE in the first place who can achieve survival and recurrence rates similar to those of patients undergoing initial RS. These are the patients who undergo early secondary radical resection (within 30 days following LE) because of high risk histological features in the excised specimens (positive margins, vascular invasion, etc.) The 5-year disease free survival of these patients is reported to reach $94 \%$. Therefore, LE as a sole therapeutic intervention is associated with considerable longterm recurrence rates even for $\mathrm{T} 1$ rectal tumors. The main reason for these results seems to be the high incidence of regional LN metastases which may reach even $22 \%$ to $34 \%$ in T1 rectal cancer overall, in comparison with 3\% to $10 \%$ in T1 cancers of the rest large intestine. Therefore, it seems that in order to have improved results from LE, this method should be included in a multi-modality therapeutic strategy (Balch et al., 2006; Garcia-Aguilar et al., 2000).

\subsection{The role of radio-chemotherapy}

The contribution of postoperative radiotherapy (RTx) following LE for T1 or T2 rectal tumors is difficult to be evaluated because of lack of large randomized trials and the large variation of reported doses (2,700-6,300 cGy) and techniques. The 5-year overall survival ranges from $67 \%$ to $80 \%$, which lies close to survival following LE alone (Bittorf et al., 2003). 


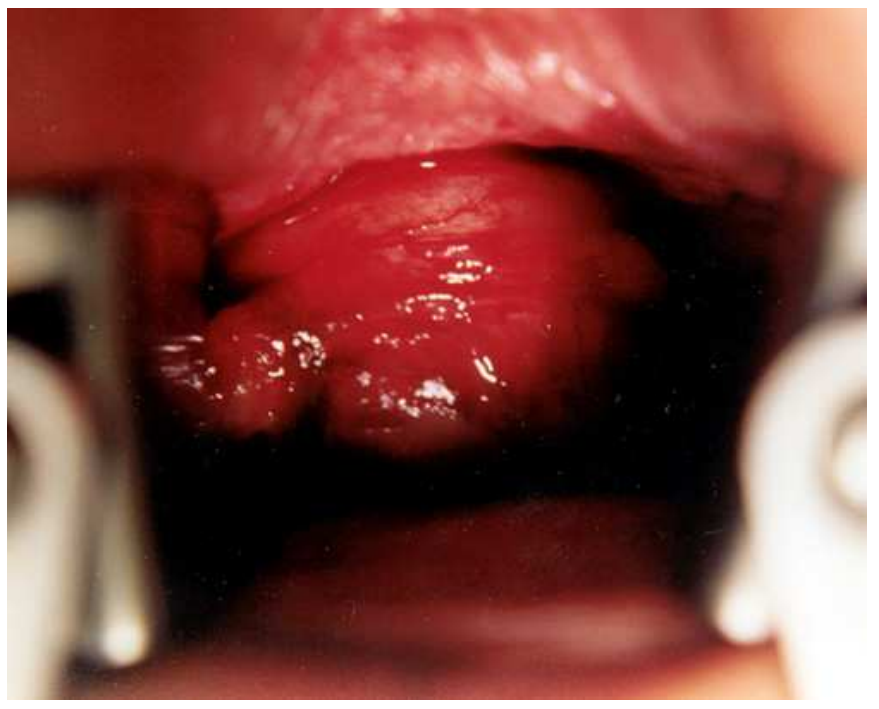

Fig. 6. Well-differentiated rectal tumor visible through the anal dilator during transanal resection.

The fact that it is usually patients with high risk prognostic features that undergo postoperative RTx and the lack of randomization explain in part the absence of improved results. The local control rate following postoperative RTx however is reported to reach $96 \%$ at 5 years, dropping to $57 \%$ at 8 years. Perhaps postoperative RTx following LE does not alter the natural history of the disease per se, but it rather seems to delay locoregional recurrence by approximately 1 year (Kurt et al., 2005; Wagman et al., 1999).

Preoperative radiotherapy or chemoradiation has been used to downstage rectal tumors and to facilitate sphincter-sparing surgery. In addition to the increased resectability of bulky rectal cancers, another benefit of neoadjuvant therapy seems to be the reduction of locoregional recurrence and the improved survival. It is reported that even T3N0 rectal cancer patients with complete clinical and pathologic response after neoadjuvant chemoradiation can achieve local recurrence and survival rates following LE equivalent to those following RS (Bonnem et al., 1999). The main limitation of suggesting conservative surgery for such patients is the accuracy of imaging methods (EUS, MRI) in restaging the original lesion, as well as the residual LN involvement following chemoradiation. Especially after radiotherapy, there is considerable difficulty to distinguish residual tumor and lymph node involvement from post radiation fibrosis. Nevertheless, $15-30 \%$ of patients seem to present reliable, complete clinical regression by endoscopic, imaging and serologic means, following neoadjuvant treatment (Mohiuddin et al., 2000).

In addition, most of these patients will show complete pathologic response as well in RS specimens. Therefore, these patients (especially elderly ones) may have the same long term results after LE. The pathologic T-stage following neoadjuvant chemoradiation and LE (YPT stage) seems to be a strong predictor of residual LN disease ( $\mathrm{YpN}$ stage). Patients with complete pathologic T regression (ypT0) have $0-24 \%$ risk for LN disease. In fact, there are small series reporting overall recurrence rates from $0 \%$ to $13 \%$ in patients with ypT0 and ypT1 lesions (Bedrosian et al., 2004; Marakis et al., 2009). 
It seems that the advances in staging technology and methodology, as well as the adoption of modern neoadjuvant multimodality strategies may provide reliable conservative surgical treatment options. Carefully selected patients (e.g. elderly ones) undergoing local excision of early rectal cancer may have similar outcome with the ones following radical surgery, when the appropriate adjuvant or neo-adjuvant treatment is applied.

\section{Abdominoperineal resection for rectal cancer}

Papadopoulos V, Michalopoulos A, Pramateftakis MG

In 1908, while investigating the pathogenesis of rectal cancer, Miles established the role of the lymphatic system in the spread of malignancy and emphasised the need for synchronous removal of the rectum and its "lymphatic drainage" with the abdominoperineal approach. Progress in medicine resulted in a decrease in post-operative deaths and allowed abdominoperineal resection (APR) to yield better long-term results as compared to trans-sacral procedures.

\subsection{Indications}

The question "Which patient with low rectal carcinoma is best treated by an APR?" has no simple answer. Many factors influence the decision to perform an APR for rectal cancer, as seen in Table 1. Surgeons have the responsibility to carefully weigh these factors, discuss all available options with the patient, and be knowledgeable and flexible in approaching those options individually for each patient (Rothenberger \& Wang, 1992).

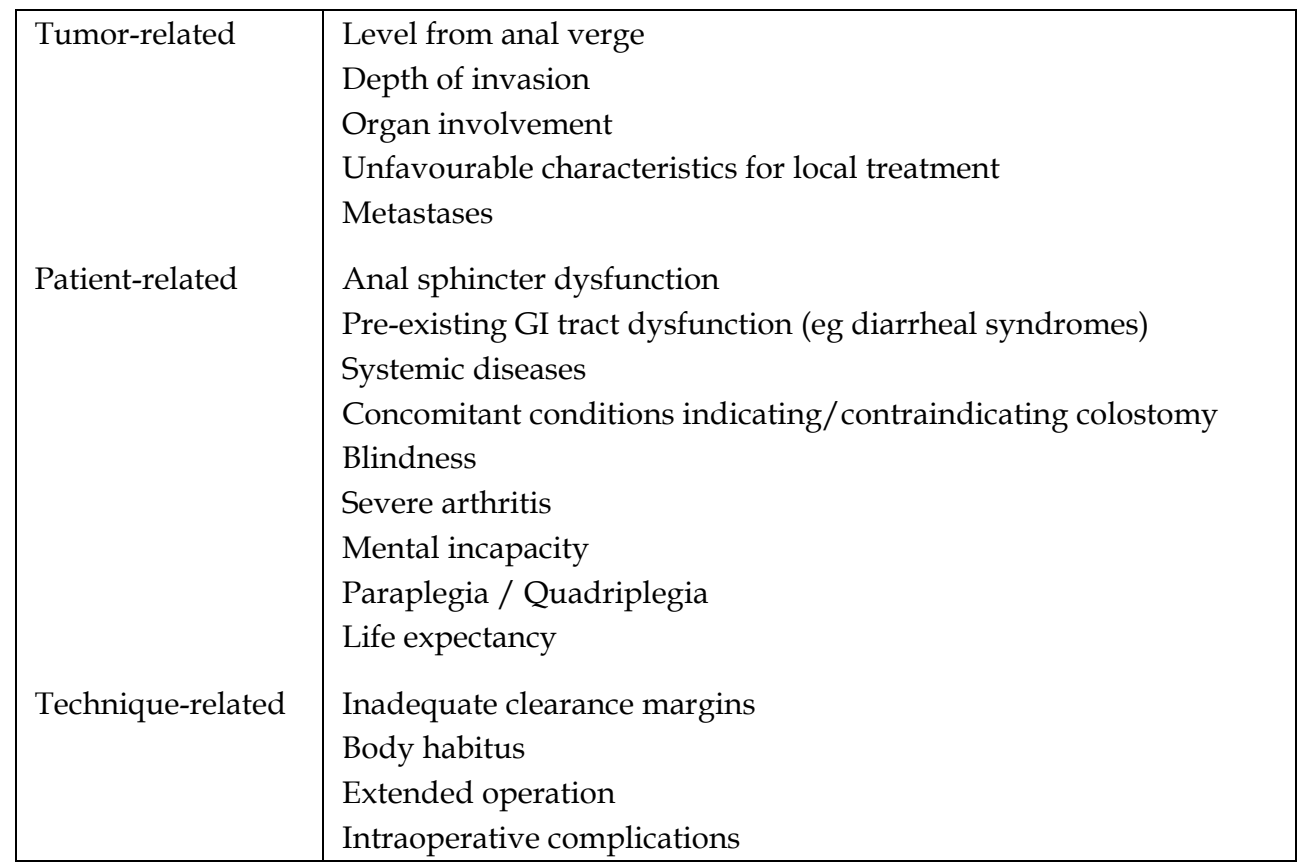

Table 1. Factors that influence the decision of performing an APR. 
The decision of the surgeon to reject sphincter-saving operations in favor of an APR should be based on a variety of variables, characteristic for the tumor and the patient. Therefore, the surgeon should make the final decision of operative technique upon completion of total mesorectal excision (TME), being certain of the absence of macro and microscopic evidence of cancer invasion in the circular and distal margin of expected resection ("rectum neck" in the area of junction to levator). An inadequacy of providing uninvaded margins can serve as an indication to perform APR.

Invasion of the dentate line or a free margin less than $1 \mathrm{~cm}$ is also an indication for an APR. Digital rectal examination and rigid proctosigmoidoscopy are typically required for accurate tumour assessment. It is undeniable that cancer of the lower rectum can serve as an indication for APR when the parietal fascia is involved, as well as when there are symptoms of lymphatic spread, regardless of the distal margin of the tumour from the dentate line.

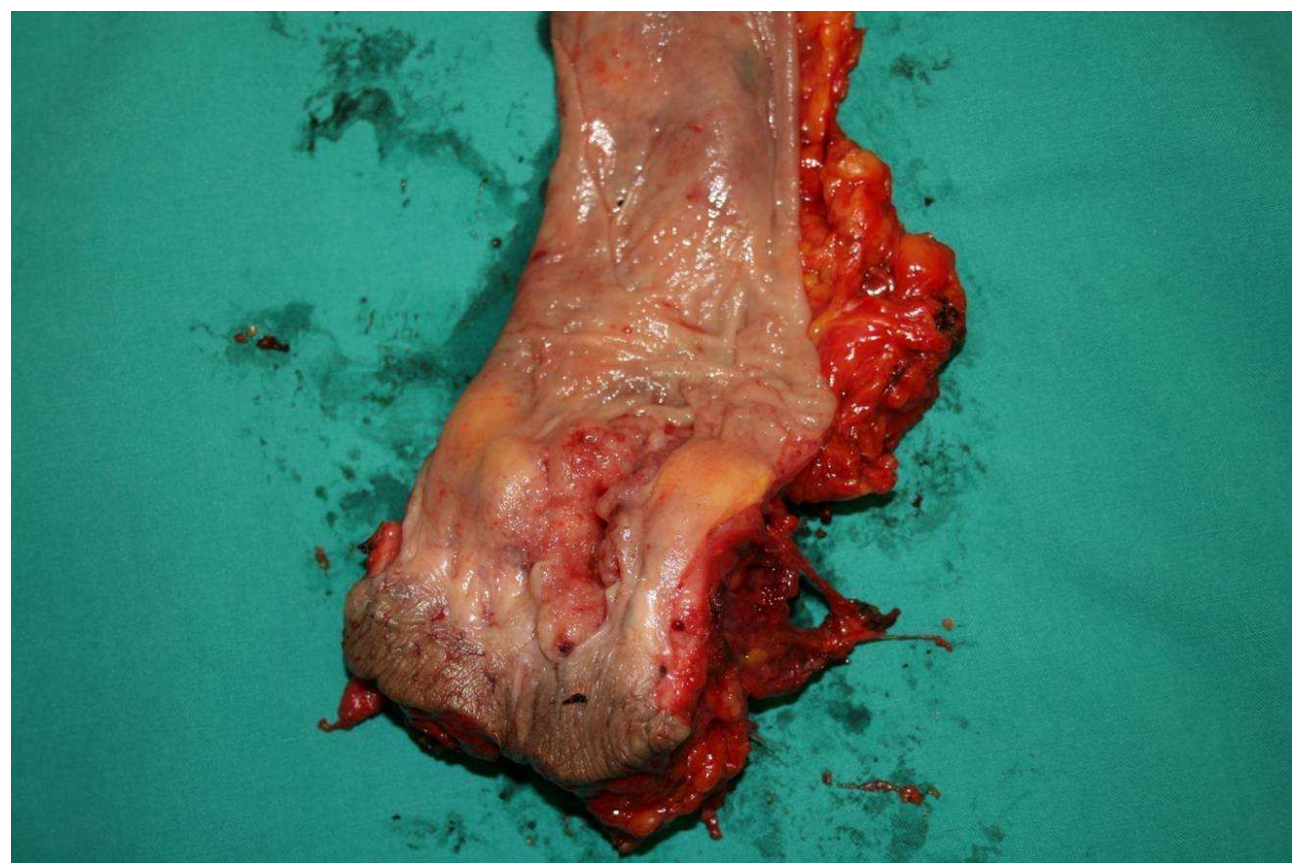

Fig. 7. Specimen following abdominoperineal resection of the rectum.

The variety of factors which can affect the surgeon's decision whether to perform resection of the rectum should include the condition of the anal sphincters, bowel function, patient's age, concomitant diseases and capability of self-care of stoma. Thus, in case of anal incontinence, for patients with adenocarcinoma located 1-2 cm from the dentate line, it is unreasonable to aim for intestine continuity, because incontinence can even deteriorate (Tsarkov, 2005).

\subsection{Contraindications}

Contraindications for the performance of APR include: 
1. Low dimensional tumors (less than $2 \mathrm{~cm}$ in diameter)

2. Tumors characterized by a high or good degree of differentiation

3. Invasion of the tumor not exceeding the submucosal layer

4. Absence of lymphovascular invasion.

In all these cases it is reasonable to apply various other procedures such as transanal local excision, transanal endoscopic microsurgery, diathermocoagulation via anoscope, etc. At the same time, the T1 or T2 tumours without involvement of the internal sphincter and longitudinal muscle in case of well differentiated adenocarcinomas located $1-2 \mathrm{~cm}$ from the dentate line cannot be considered as an implicit indication for APR. These tumours should be judged from the viewpoint of the possibility of implementing resection of the rectum with subsequent formation of either ultralow stapled colorectal or hand-sutured colo-anal anastomosis.

\subsection{Postoperative care, complications and mortality}

Following pelvic dissection, there is some laxity of the anterior support as well as swelling and edema due to the procedure, which may lead to voiding difficulties in the first few days, particularly in male patients. The pelvic and abdominal drains are left in situ until they drain less than $50 \mathrm{ml}$ daily.

The operative mortality after an abdominoperineal resection should be less than $2 \%$. As with all forms of major abdominal surgery, improved anesthesia techniques and invasive perioperative monitoring have allowed the reduction in mortality from $42 \%$ reported by Miles in 1908 (Chiappa et al., 2006; Peparini et al., 2006). Today, the majority of operative mortality in reported series is related to cardiopulmonary and septic complications. While mortality is relatively low, morbidity varies from 15\% to 35\% (Nissan et al., 2001; Piso et al., 2004).

A prospective randomized trial demonstrated that laparoscopic-assisted APR offers better immediate outcomes in terms of faster return of bowel function, earlier mobilization and less analgesic requirements when compared with open surgery for low rectal cancer, but at the expense of longer operative times and higher cost. Oncological clearance and long-term survival are seemingly not jeopardized by the laparoscopic-assisted approach ( $\mathrm{Ng}$ et al., 2008). After rectal cancer surgery, postoperative general complications occur in $20-35 \%$ of all patients and postoperative hospital stay is 5-7 days. "Fast-track" rehabilitation has been shown to accelerate recovery, reduce general morbidity and decrease hospital stay after elective rectal surgery (Schwenk et al., 2006).

\subsection{Complications of APR}

The potential benefit of surgery should be measured against the morbidity associated with pre-existing conditions not related to the primary disease and which may jeopardize the surgical outcome. Complications are related to the patient's fitness, the operative procedure, surgical technique and anaesthesia. Therefore the surgeon's role, besides careful patient selection and preoperative optimisation of pre-existing medical conditions, extends to a level of knowledge and technical skill that should minimise early and late complications (Tsarkov, 2005).

\subsubsection{Ureteric injury}

The ureters are prone to injury in any pelvic operation. Such injuries can occur during either the abdominal or perineal phase of an APR. Care should be taken to identify and protect the 
ureters intra-operatively. During an APR for recurrent carcinoma and for very extensive rectal cancers, consideration may be given to the use of ureteric stents to aid the ureter identification. The incidence of ureteral injury in large published series has been variable. Eickenberg and colleagues reported ureteral obstruction in 7 out of 100 patients undergoing APR but could not distinguish whether this was due to intra-operative injury or other causes. The major morbidity from ureteric trauma is the unrecognized injury that presents later as an obstruction or fistula (Eickenberg et al., 1976).

\subsubsection{Compartment syndrome}

One of the concerns of placing the patient in the lithotomy position is its association with the development of a compartment syndrome. This occurs when elevated pressure in an osteofascial compartment compromises local perfusion. This can result in neurovascular damage and permanent disability, emphasizing the importance of prevention and early diagnosis. Intermittent, sequential compression of the lower limbs is strongly encouraged to prevent venous stasis (Boulos \& O’Bichere as cited in Hakim \& Papalois, 2007).

\subsubsection{Abdominal Haemorrhage}

Haemorrhage is either primary or secondary. Primary bleeding at the time of surgery or in the immediate postoperative period is the result of poor surgical technique and the failure to achieve satisfactory haemostasis. Clotting disturbances due to massive transfusions and restoration of blood pressure with fluid replacement or drug therapy may be contributing factors. Secondary haemorrhage occurring 7-10 days after surgery is attributed to a dislodged blood clot, dissolution of ligature materials or erosion of a vessel due to an intraabdominal infection.

\subsubsection{Pelvic Haemorrhage}

In cases when there is locally advanced or recurrent cancer, previous pelvic surgery or preoperative radiotherapy, pelvic dissection of the rectum should be undertaken with extreme care. Rarely, a middle sacral artery over the sacral promontory or a left common iliac vein is injured at the start of the pelvic dissection. The lower pelvic side walls may cause significant bleeding when the pelvic fascia is pulled medially by fibrosis or tumour tethering leading to dissection outside the fascia that may injure the internal iliac vessels. Dissection along the correct plane is avascular down to the lateral ligaments which are then divided by clamping or ligation.

Presacral haemorrhage is sometimes unavoidable when the presacral fascia (overlying the high pressure anterior venous plexus) is disrupted or if it is densely adhered to the mesorectal fat. Presacral haemorrhage can also occur from an injury to the anterior presacral plexus or the basivertebral veins during the placement of rectopexy sutures. Significant haemorrhage can occur if the basivertebral veins are divided at the level of the lower sacral foramina. These veins communicate with the internal vertebral venous system, a large valve-less venous system that communicates with the inferior vena cava. The rapid blood loss associated with this injury is related to high hydrostatic pressure in the depth of the pelvis accentuated in the lithotomy position, which increases venous pooling within the pelvis. In most instances bleeding can be controlled by packing, suture ligation, clips or cautery. These will be ineffective if the basivertebral veins are injured at the sacral foramina, due to the fact that these large veins tend to retract themselves into the sacral foramina 
when injured. Bone wax or thumbtacks are employed to occlude the foramina and stop the bleeding (Boulos \& O'Bichere as cited in Hakim \& Papalois, 2007).

\subsubsection{Small bowel obstruction}

Mechanical bowel obstruction that occurs early in the postoperative period is commonly caused by fibrinous adhesions before they become organised by the invasion of fibroblasts and sprouting capillaries to form permanent fibrous adhesions. It is less frequently a result of internal herniation, volvulus, anastomotic edema, intraperitoneal haematoma or abscess. The appearance of a paralytic ileus is variable after abdominal surgery and is due to reflex inhibition of normal peristalsis. It is painless and lasts for a few days but is prolonged by visceral injury, abdominal sepsis or bleeding, immobility and some medications (atropine, ganglion blocking agents, diuretics).

\subsubsection{Genitourinary complications}

Other than operative trauma genitourinary complications comprise voiding and sexual dysfunction related to neurological damage during a pelvic dissection which might be unavoidable particularly in resections for advanced carcinomas. However with knowledge of the pelvic anatomy, surgical technique can be refined, exercising caution where nervous structures are particularly vulnerable, hence minimising the risk of these complications and improving the quality of life (Eickenberg et al., 1976; Tsarkov 2005).

\subsubsection{Bladder injuries \& voiding dysfunction}

The bladder is exposed to injury during exploration via a lower incision of the abdomen or due to adhesions from previous surgery. An accidental cystotomy in the anterior surface of the bladder is easily repaired with two layers of continuous absorbable suture, and a urinary catheter is left in situ for 7 days. Injury to the posterior bladder wall can occur when mobilising an inflammatory or neoplastic recto-sigmoid mass or during perineal excision of the rectum. The repair of such an injury is more demanding, especially if the injury is at the base of the bladder. In that case, a urologist should be involved because of the risk of damaging the ureters during the repair. This can be carried out from inside the bladder through an anterior cystotomy, whereby ureteric stents are passed retrogradely to ensure their patency.

Undetected injuries will manifest as a vesicoperineal fistula or an enterovesical fistula. Vesicoperineal fistulae are recognised by the leakage of urine through the perineal wound. The diagnosis is confirmed by a cystogram. Small fistulae may close with urethral or suprapubic catheter drainage for a minimum duration of 6 weeks.

Urinary problems constitute the most frequent and troublesome complications following an APR. Urinary tract infections are very common, occurring in 6-32\% of patients (Piso et al., 2004). Contributing factors include the use of urinary catheters and urinary stasis. While bladder neck or prostate angulations may be contributory, the majority of micturition disturbances are due to neurologic injuries. As voiding dysfunction following an APR is common and transitory, one can expect it to subside within three to six months postoperatively.

Fowler et al warned that if large volume retention in the post-operative period secondary to bladder denervation is not recognised and remains untreated, bladder rehabilitation and restoration of normal voiding may be impossible. Many authors advocate the use of 
urodynamic studies in order to identify patients at risk of developing urinary problems and to detect early post-operative voiding dysfunction (Fowler et al., 1978).

Urinary dysfunction is of particular interest in the evaluation of the nerve-preserving procedure effectiveness. The parasympathetic nerve supply is responsible for bladder contraction. Furthermore, the sympathetic nerve supply allows relaxation of the bladder wall and contraction of the bladder neck while the perineal branch of the pudendal nerve supplies the external urethral sphincter. Early complications are recognised on removal of the urinary catheter and include urinary retention, infection and incontinence due to posterior bladder displacement after abdomino-perineal excision of the rectum, neurologic injury and pre-existing outlet obstruction precipitated by epidural anaesthesia, general anaesthesia, prolonged bed rest and alpha-agonist and anticholinergic medication. Recatheterisation, antibiotics, withdrawing drugs that contribute to urinary retention and a trial of alpha-adrenergic blockers are simple but often effective measures.

Patients with urinary symptoms that continue for longer than 6 weeks after surgery should undergo urodynamic studies to determine the nature of the injury and differentiate it from a simple outlet obstruction requiring prostatectomy (Boulos \& O'Bichere as cited in Hakim \& Papalois, 2007; Eickenberg et al., 1976; Tsarkov 2005).

\subsubsection{Sexual dysfunction}

This is more common in males than females because of the anatomical relationship of the rectum to the nerves responsible for the sexual function and due to a better understanding of the male sexual response and disorders that follow pelvic surgery. Women suffer decreased libido, difficulty with orgasm and most commonly dyspareunia. Male dysfunction includes erectile difficulty, retrograde ejaculation and total impotence. Sexual dysfunction is more likely in patients of higher age and after resections for cancer than inflammatory bowel disease, due to the fact that dissection in this case is close to the rectal wall and perineal excision is performed in the intersphincteric plane.

Male sexual dysfunction is regulated by the autonomic nervous system via the pelvic plexus which lies posterolateral to the bladder. Sympathetic nerves are responsible for ejaculation, while parasympathetic nerves govern erection. $15 \%$ of patients with normal sexual function prior to an APR are expected to experience some kind of sexual dysfunction (Boulos \& O’Bichere as cited in Hakim \& Papalois, 2007).

\subsubsection{Perineal complications}

Wound infections, perineal hernias, delayed healing and very rare chronic perineal sinuses are complications occurring at the perineal site. Only few patients require surgical intervention for such complications. Perineal wound infection is associated with closure rather than with open packing of the perineal wound especially when excision of the rectum is complicated by faecal contamination. Treatment consists of wound opening and local care. Nevertheless, the wound might not heal and if it remains unhealed for more than six months it is then defined as a perineal sinus.

\subsubsection{Stoma complications}

An array of stomal complications can occur in patients undergoing APR, as seen in table 2 . The majority of these are preventable by careful attention to site selection and operative technique. Complications are more frequently encountered in unplanned stomas, in obese patients and in elderly patients. 


\begin{tabular}{|l|l|}
\hline Stoma complications & Aetiology \\
\hline Ischemia / Necrosis & $\begin{array}{l}\text { Inadequate blood supply } \\
\text { Excessive mesenteric stripping }\end{array}$ \\
\hline Haemorrhage & Inadequate haemostasis \\
\hline Abscess formation & $\begin{array}{l}\text { Faecal spoilage / Haematoma } \\
\text { Wall perforation by sutures }\end{array}$ \\
\hline Stoma retraction & Excessive bowel tension \\
\hline Stenosis & $\begin{array}{l}\text { Ischaemia } \\
\text { Inadequate skin aperture }\end{array}$ \\
\hline $\begin{array}{l}\text { Parastomal hernia } \\
\text { Prolapse }\end{array}$ & $\begin{array}{l}\text { Oversized abdominal wall aperture } \\
\text { Inadequate fixation / repair } \\
\text { Excessive stoma length } \\
\text { Redundant sigmoid }\end{array}$ \\
\hline
\end{tabular}

Table 2. Complications following stoma formation for APR.

Skin problems such as skin irritation are usually the result of a flush or retracted stoma, an improperly placed stoma and allergy to adhesive materials on the bag. With strict hygiene, skin barriers and local antimicrobials the majority of these skin problems are easily manageable. A subcutaneous infection can lead to the formation of a fistula. The latter can be avoided by adjusting the size of the abdominal wall opening to the size of the bowel and by preserving the subcutaneous fat, in order to avoid creating dead space, prone to the formation of haematomas and infection.

Necrosis is the result of skeletonization of the terminal bowel and inadequate abdominal wall opening particularly if the mesentery is thickened due to fat or inflammation. A colour change of a stoma is more likely to be due to ischaemia rather than to venous engorgement or submucosal haematoma if the stoma does not feel warm and there is no arterial ooze from the mucosa on pin-prick. The level of necrosis should be determined by examining the stoma with a paediatric proctoscope or a flexible endoscope as this guides further management. The long-term result of superficial necrosis is stenosis and the stoma can be revised by local exploration. Necrosis below the fascia, therefore intraperitoneally, requires immediate exploration via a laparotomy. Tension on the stoma, improper construction or ischaemia are responsible factors. An abdominal opening that is wider than the bowel lumen causes tension on the mucocutaneous sutures which break and the stoma separates itself from the skin. Stoma retraction may occur as a late complication if a patient gains excessive weight.

Stenosis, often due to ischaemia, is a common cause of colostomy obstruction. The obstruction resolves spontaneously or by saline irrigation of the colostomy through a Foley catheter. Careful dilatation with the finger or graduated dilators can also be attempted in a stenosed stoma. If these measures fail to relieve obstruction, refashioning of the stoma is considered and this will probably require re-exploration, due to the fact that at this early stage local revision can be technically difficult and not safe due to inflammation and oedema at the stoma site. Stenosis identified at a later stage can be revised locally at least 3 months after the initial procedure, as fibrosis becomes established and the tissue planes are better defined to allow exteriorisation of a fresh segment of the bowel for fashioning of a new stoma. 


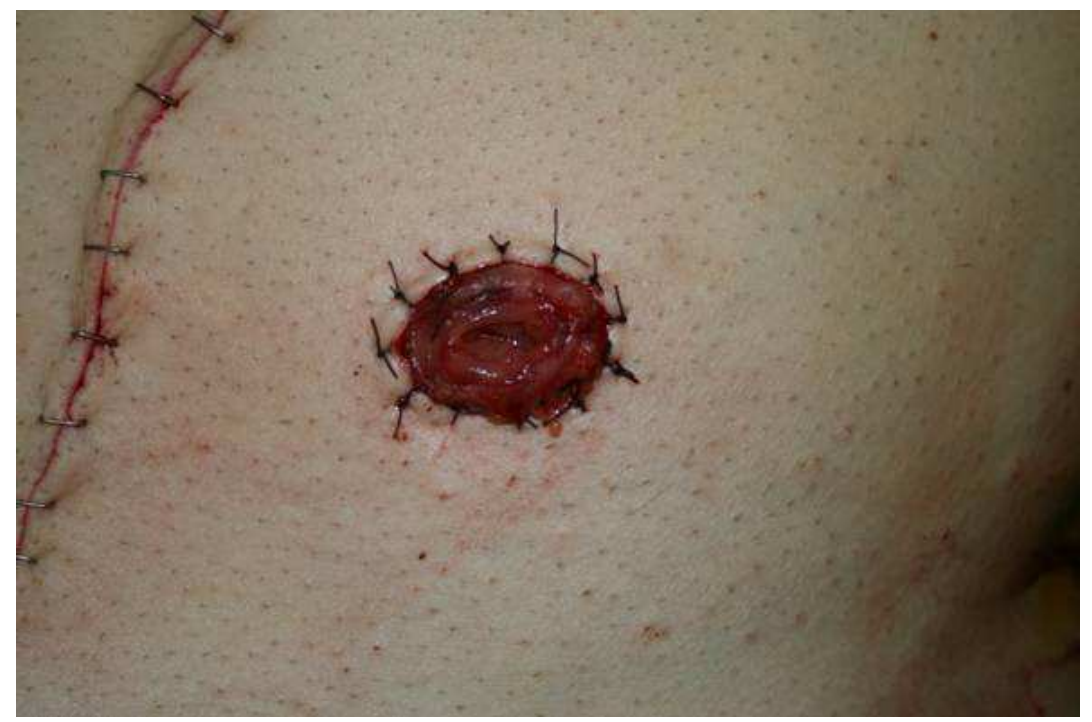

Fig. 8. End colostomy following APR.

A parastomal hernia is the commonest complication following stoma formation. Predisposing factors are obesity, chronic respiratory disease and a predisposition to other abdominal hernias. Ideally, the colostomy should be sited over the rectus muscle and brought out through the split thickness of the muscle. Parastomal herniation is less likely to occur if the stoma is fashioned through the muscle rather than at the side of the rectus muscle. Furthermore, the stoma should ideally be situated below the belt-line at a distance from the bony promontories and the umbilicus. Local repair may involve suture approximation of the defect with or without mesh reinforcement and if this fails, reciting of the stoma may become necessary.

Colostomy prolapse is usually associated with a parastomal hernia, and is more common in obese patients. The prolapse, which is an intussusception of the proximal bowel, is easily reducible even by the patients themselves. Elective surgical treatment consists of excision of the redundant colon followed by local repair of the parastomal hernia (Boulos \& O'Bichere as cited in Hakim \& Papalois, 2007).

\subsection{Oncologic outcomes: Local recurrence \& survival following APR}

Recent literature has shown that the local recurrence (LR) of lower rectal cancers is higher, compared to the middle and upper ones (Daniels et al., 2006). This may be due to a lack of mesorectum below the levator sling, which increases the chance of tumor spread to the perirectal tissues, increasing the risk of the surgical resection margin being invaded by tumor. In addition to that, low rectal cancers present with more significant factors that predict recurrence, such as lymphatic and vascular invasion, perineural invasion and positive nodal disease. Other factors are involvement of the circumferential resection margin (CRM), tumor distance from the anal verge, tumor differentiation, nodal status, extent of extramural spread and peritoneal perforation by the tumor (Birbeck et al., 2002; Hermanek et al., 1989).

In Heald's series, $45 \%$ of patients had cancers in the lower rectum. Of the patients who had a curative LAR, the 5-year LR rate was $7 \%$ and systemic recurrence rate was $27 \%$, compared 
with $17 \%$ and $27 \%$ in patients who had curative APR. The LR rate after an APR tends to be higher than for LAR in most series comparing rectal cancers of all stages, with a range of 10 $33 \%$ (Dehni et al., 2003). This comes in contrast with a LR rate of $4-8 \%$ for anterior resection with TME for all stages of rectal cancer, as reproduced by Enker in the USA (Enker et al., 1995). Studies by Quirke have shown that an involved CRM and the depth of extramural invasion are independent markers of poor prognosis and correlate with high LR rates due to residual microscopic disease. In patients with an involved CRM, the LR rate was 64\%, compared with $9 \%$ in patients with a clear CRM (Quirke et al., 1988). Recent data suggests that a CRM at risk of tumor involvement can be accurately predicted on preoperative MRI.

Marr et al examined the cause of LR and patient survival following APR and LAR for rectal carcinoma and the effect of TME (Marr et al., 2005). There was a significant difference in both LR rates $(23.8 \%$ versus $13.5 \%, p=0.002)$ and cancer-specific 5-year survival $(52.3 \%$ versus $65.8 \%, \mathrm{p}=0.003$ ) between the APR and LAR groups. The conclusion of the study was that patients treated by an APR have a higher rate of CRM involvement, a higher LR and poorer prognosis than LAR. The frequency of CRM involvement for an APR has not diminished with TME. CRM involvement in the APR specimens is related to the removal of less tissue at the level of the tumor. Where possible, a more radical operation should be considered for all low rectal cancer tumors. The high rates of LR following APR could be explained by a number of factors. APR may be associated with a different pattern of lymphatic spread, which is not included in the "tumor package" excised by TME, or inadequate surgical resection may occur in a higher proportion of patients (Marr et al., 2005). Lymphatic spread to the iliac or obturator nodes occurs and removal of these nodes is reported as a determinant of LR. Inadequate excision appears to be the major factor determining outcome.

In advanced extraperitoneal rectal cancer, Japanese surgeons perform a lateral pelvic nodal dissection with only partial pelvic autonomic nerve preservation. Most Western surgeons prefer the total mesorectal excision (TME) with complete pelvic nerve sparing except for the cases with evident neoplastic neural involvement. Another study was performed to identify long-term oncological results of the total nerve-sparing TME between LAR and APR. The 5year overall and disease-free survival rates were $88.8 \%$ and $77.7 \%, 90 \%$ and $75.1 \%$ and $62.3 \%$ and $45 \%$ for stage I, II and III respectively. The 8 -year overall and disease-free survival rates were $77.7 \%$ and $77.7 \%, 78.3 \%$ and $75.1 \%$ and $50.4 \%$ and $40 \%$ for stage I, II and III respectively (Peparini et al., 2006).

It has been shown that staging MRI can define the mesorectal fascia and its proximity to the tumor and thereby help identify the expected TME resection margin. This should be extended to early pT1/pT2 low rectal cancers with the possible addition of EUS. The identification of the proximity of the expected surgical CRM to the tumor in the low rectum is an important challenge to the radiologist in order to predict the likelihood of complete excision. pT3 low rectal cancers are unlikely to be completely excised by surgery, and either wider surgical excision with en bloc removal of the levators and anal sphincters or a reduction of the tumor size by preoperative radiochemotherapy is required. Over the last years, there is a trend towards accurate MRI staging and preoperative radio-chemotherapy. Adjustments to the treatment of low rectal cancer are urgently required to achieve the lower rates of involvement of the CRM that are now obtained following mesorectal excision for high and mid rectal excisions. This should greatly improve local recurrence rates and 5-year survival in patients with such disease (Christoforidis et al., 2004; Marr et al., 2005). 
Another study was performed by den Dulk in order to identify tumor and patient related risk factors in patients with distal rectal cancer treated by an APR and associated with positive CRM, LR and overall survival. It is concluded that anterior tumor location, advanced T-stage, and higher $\mathrm{N}$-stage were independent risk factors for positive CRM. Positive CRM, higher T-stage, and higher N-stage were risk factors for local recurrence. In addition to the risk factors for LR, distal tumor location and older age were associated with reduced overall survival (den Bulk et al., 2007).

Preoperative chemoradiotherapy (CRT) has contributed remarkably to the increase of sphincter-preserving procedures (SPP) for lower rectal cancer. Kim et al compared the outcomes between APR and SPP after preoperative CRT in patients with locally advanced lower rectal cancer. Patients who underwent APR had a higher 5-year local recurrence $(22.0 \%$ vs $11.5 \%, \mathrm{p}=0.028)$ and lower 5 -year cancer-specific survival rate $(52.9 \%$ vs $71.1 \%$, $\mathrm{p}=0.03$ ) compared to patients who underwent SPP. This study shows that APR following preoperative CRT exhibited more adverse oncologic outcomes compared to SPP. This result may be due to higher rates of CRM involvement in APR even following preoperative CRT. The authors suggest that sharp perineal dissection and wider cylindrical excision at the level of the anorectal junction are required to avoid CRM involvement and improve oncologic outcomes in patients who undergo APR following preoperative CRT (Kim et al., 2009).

With regards to whether specific histopathological parameters can predict local recurrence, Dresen et al studied $\mathrm{T}_{\mathrm{x}} \mathrm{N}_{\mathrm{x}} \mathrm{M}_{0}$ patients treated for locally recurrent rectal cancer over a period of 12 years. These patients were matched with a control group of patients who did not develop LR after primary rectal cancer treatment for at least 2 years based on the type of neoadjuvant treatment in an 1:2 ratio. The pathology of all primary rectal cancers was reviewed. Patient, treatment and histopathological characteristics were studied in relationship with the development of LR. The results indicate that the presence of lymphovascular invasion (LVI), extramural venous invasion (EMVI), positive CRM, serosal involvement and poor differentiation are factors leading to an increased risk of LR. However, higher age was a protective factor. The study concluded that apart from a positive CRM and serosal involvement, LVI, EMVI and poor differentiation are important independent predictive factors for the development of LR. Adjuvant therapy may be considered in the presence of these features in order to decrease the risk of a local recurrence (Dresen et al., 2009).

Laparoscopic resection for rectal cancer is feasible and safe, with acceptable morbidity and long-term results in patients receiving neoadjuvant treatment. In a study by Pugliese et al, the 5-year survival rate was $74.6 \%$ after laparoscopic LAR and 53\% after laparoscopic APR (Pugliese et al., 2009). Baek et al, in an effort to evaluate oncologic outcomes after roboticassisted LAR and APR with TME, analyzed prospectively sixty-four consecutive rectal cancer patients with stage I-III disease. The study showed that the CRM was negative in all surgical specimens, no port-site recurrence occurred in any patient and 6 patients developed recurrence: 2 combined local and distant, and 4 distal alone (mean follow-up of 20.2 months). None of the patients developed isolated local recurrence. The mean time to local recurrence was 23 months and 3-year overall and disease-free survival rates were $96.2 \%$ and 73.7\%, respectively (Baek et al., 2010; Kanellos D et al., 2010).

\subsection{Functional outcomes and quality of life}

Avoiding a permanent stoma following rectal cancer excision is believed to improve quality of life (QoL), but evidence from comparative studies is contradictory. The results of a metaanalysis comparing QoL following APR with that after LAR in patients with rectal cancer 
show that the argument for restorative resections for rectal cancer cannot hinge solely on the issue of a perception of superior QoL outcomes for patients. It is clear that the preconception of many surgeons and patients is that QoL will be better if a permanent stoma is avoided. To the contrary, patients undergoing APR experience postoperatively a global QoL incorporating the physical and psychological effects of treatment with or without a permanent stoma - that appears to be equivalent to that after LAR. Overall measures of QoL, measured using a variety of validated tools, are not significantly different between APR and LAR patients, but further comparative studies with longer periods of follow-up are needed. Individual domains do highlight significant differences between the two surgical approaches which may help the preoperative decision making process, but individualisation of care incorporating QoL outcomes and functional, oncological and technical considerations is essential for rectal cancer patients (Cornish et al., 2007).

Emotional and cognitive scores from the QLQ C30 questionnaire were consistently shown to be better for APR patients, while physical function was shown to be better for LAR patients using both tools. The improved emotional scores for APR patients may represent the finality of the treatment, as a patient no longer needs to be concerned about invasive examinations of the lower GI tract or worry about future complications once healed adequately.

While some authors have reported that functional recovery following LAR is complete by the $6^{\text {th }}$ postoperative month, others have suggested that at 1 year following LAR, stool frequency is still significantly higher than that preoperatively and that the so-called "anterior resection syndrome" lasts for at least 1 year (Kakodkar et al., 2006).

The decision of which operation to perform would depend on a number of variables, including the likely oncological outcome, the life expectancy of the individual patient and their attitude towards a permanent stoma. There is evidence to suggest that oncological outcomes such as circumferential resection margins and rates of local recurrence are less favourable following APR than LAR. Such results may reflect technical factors that render APR a more complex procedure or differences in anatomy and tumour biology that may negatively impact on lower rectal tumours, which are more likely to be treated with sphincter-sacrificing surgery. In some cases, however, the height of the lesion will necessitate APR, as even ultra-low LAR with inter-sphincteric dissection will be inadequate to permit a safe oncological excision (Tekkis et al., 2005).

The overall findings of the meta-analysis by Cornish et al, highlighting no overall difference in QoL between those patients with and without permanent stomas, challenge the conclusions that may be drawn from other reports which have highlighted rates of stomarelated complications of up to $34 \%$, with deterioration in overall lifestyle and sexual activity by $80 \%$ and $43 \%$, respectively. Meta-analyses of individual domains from the QoL instruments suggested improved cognitive, emotional and future perspective scores for those undergoing APR (Cornish et al., 2007).

\section{Treatment algorithm for cancer of the rectum}

\section{Pramateftakis MG, Spanos K, Tepetes $K$}

Treating rectal cancer certainly requires a multidisciplinary approach involving surgery, radiology, pathology and oncology. Even though chemoradiotherapy has made huge advances over the last years, especially in the form of neoadjuvant therapy, radical surgery and lymphatic clearance remain the key elements to treating rectal cancer. It is therefore 
crucial to say that designing a treatment plan should be "individualised" to each patient, depending on location and stage of the disease (Kanellos et al., 2010).

Pre-operative tumor staging will determine the tumor stage. Depending on the $\mathrm{T}$ stage of the cancer, three treatment categories can be identified: The early stage, the intermediate stage and the advanced stage cancer. The treatment approach one should follow is shown in Table 3:

\begin{tabular}{|l|l|}
\hline \multicolumn{1}{|c|}{ Cancer stage } & \multicolumn{1}{c|}{ Treatment } \\
\hline Early cancer (T1) & Local transanal resection / Radical resection \\
\hline Intermediate cancer (T2) & $\begin{array}{l}\text { Radical resection followed by adjuvant } \\
\text { chemo-radiotherapy (depending on N status) }\end{array}$ \\
\hline Advanced cancer (T3,T4) & $\begin{array}{l}\text { Neo-adjuvant chemo-radiotherapy followed } \\
\text { by major radical resection }\end{array}$ \\
\hline
\end{tabular}

Table 3. Treatment according to stage.

After the decision on the treatment plan has been made, the surgeon has to decide on his approach to the tumor. The position of the tumor with regards to the dentate line plays a significant role in the approach chosen by the surgeon, a fact that was analyzed in detail in the previous chapters. Therefore, depending on the tumor distance from the dentate line, four treatment categories can be identified. These are shown in Table 4:

\begin{tabular}{|c|c|c|}
\hline Distance & Stage & Approach \\
\hline$\geq 4-5 \mathrm{~cm}$ from dentate line & T1-T4 & Low anterior resection \\
\hline$<4 \mathrm{~cm}$ from dentate line & $\begin{array}{l}\text { T1 (well-differentiated, } \\
<3 \mathrm{~cm} \text { diameter) }\end{array}$ & Transanal resection \\
\hline $1-3 \mathrm{~cm}$ from dentate line & $\begin{array}{c}\text { T1 or T2 with "un- } \\
\text { favourable" characteristics }\end{array}$ & Intersphincteric resection \\
\hline $0-3 \mathrm{~cm}$ from dentate line & T3-T4 & $\begin{array}{l}\text { Abdominoperineal } \\
\text { resection }\end{array}$ \\
\hline
\end{tabular}

Table 4. Treatment according to location.

\section{Conclusion}

\section{Pramateftakis $M G$}

In order to be successful in treating rectal cancer, good oncologic outcome is the first priority. Equally important is the achievement of an acceptable quality of life for the patient. The avoidance of a permanent stoma, with all of the concomitant morbidity associated with it, may be of greater importance to the patient.

Despite advances in surgical technique along with improvements in neoadjuvant and adjuvant therapy, the surgical treatment of rectal cancer involving the pelvic floor and sphincter complex remains complicated. The decision on the type of surgery to perform depends on a number of variables including stage of the disease, tumour characteristics, condition of the anal sphincter mechanism, bowel function, patient's age, concomitant diseases, life expectancy and capability of stoma self-care. 
Why are survival rates worse after abdominoperineal resections compared to low anterior resections? Patients with very low rectal cancer treated by an APR have worse tumor characteristics and higher involved margin rates compared to patients treated by LAR. Furthermore, they have more locally extensive tumors despite a greater proportion undergoing neoadjuvant treatment. Patients with low rectal cancer pose difficulties with regards to optimal management. Targeted strategies are needed to improve outcome in this complex and common cancer.

Careful patient selection, high quality preoperative imaging and functional assessment, with emphasis on sound operative technique should lead to superior results.

\section{References}

Akasu T, Takawa M, Yamamoto S, et al. (2008). Intersphincteric resection for very low rectal adenocarcinoma: univariate and multivariate analysis of risk factors for recurrence. Ann Surg Oncol; 15(10): 2668-2676

Baek JH, McKenzie S, Garcia-Aguilar J \& Pigazzi A. (2010). Oncologic outcomes of roboticassisted total mesorectal excision for the treatment of rectal cancer. Ann Surg; 251(5): 882-886

Balch G, Ce Meo A \& Guillem G. (2006). Modern management of rectal cancer: A 2006 update. World J Gastroenterol; 12(20): 3186-3195

Bayar S, Saxena R, Emir B, et al. (2002). Venous invasion may predict lymph node metastasis in early cancer. Eur J Surg Oncol; 28(4): 413-417

Bedrosian I, Rodrifuez-Bigas MA, Feig B, et al. (2004). Predicting the node-negative mesorectum after preoperative chemoderation for locally advanced rectal carcinoma. J Gastrointest Surg; 8: 56-62.

Bennet RC. (1986). Abdomino-anal pull-through resection of the rectum. Ann Chir Gynaecol; 75: $95-9$

Birbeck KF, Macklin CP, Tiffin NJ, et al. (2002). Rates of circumferential resection margin involvement vary between surgeons and predict outcomes in rectal cancer surgery. Ann Surg; 235: 449-457.

Bittorf B, Stadelmaier U, Merkel S, et al. (2003). Does anastomotic leakage affect functional outcome after rectal resection for cancer? Langenbecks Arch Surg; 387: 406-410

Bleday R \& Garcia-Aguilar J. (2007). Surgical Treatment of Rectal Cancer, In: The ASCRS Textbook of Colon and Rectal Surgery. Springer, XXIV, pp. 413-436

Bonnem M, Crane C, Vauthey JN, et al. (1999). Long-term results using local excision after preoperative chemoradiation among selected T3 rectal cancer patients. Int J Radiat Oncol Biol Phys; 44: 1027-1038

Boulos PB \& O'Bichere A. (2007). Complications of colorectal surgery, In: Surgical complications - Diagnosis and Treatment, Hakim NS, Papalois VE, pp. 363-390, Imperial College Press

Bouvet M, Milas M, Giacco GG, et.al. (1999). Predictors of recurrence after local excision and postoperative chemoradiation therapy of adenocarcinoma of the rectum. Ann Surg Oncol; 6(1): 26-32

Branagan G \& Finnis D. (2005). Wessex Colorectal Cancer Audit Working Group. Prognosis after anastomotic leakage in colorectal surgery. Dis Colon Rectum; 48(5): 1021-1026 
Bretagnol F, Rullier E, Laurent C, et al. (2004). Comparison of functional results and quality of life between intersphincteric resection and conventional coloanal anastomosis for low rectal cancer. Dis Colon Rectum; 47: 832-838

Carlsen E, Schlichting E, Guldvog I, et al. (1998). Effect of the introduction of total mesorectal excision for the treatment of rectal cancer. Br J Surg; 85: 526-529.

Chamlou E, Parc Y, Simon T et al. (2007). Long term results of intersphincteric resection for low rectal cancer. Ann Surg; 246: 916-922

Chen CC, Lee RC, Lin JK, et al. (2005). How accurate is magnetic resonance imaging in restaging rectal cancer in patients receiving preoperative combined chemoradiotherapy; Dis Colon Rectum; 48: 722-728

Chen CC, Leu SY, Liu MC, et al. (2005). Transanal local wide excision for rectal adeonocarcinoma. Hepatogastroenterology; 52(62): 460-463

Chiappa A, Biffi R, Bertani E, et al. (2006). Surgical outcomes after total mesorectal excision for rectal cancer. J Surg Oncol; 94(3): 182-93

Christoforidis E, Kanellos I, Tsachalis T, et al. (2004). Locally recurrent rectal cancer after curative resection. Tech Coloproctol; 8: 132-134.

Compton CC, Fielding LP, Burgart LJ et al. (2000). Prognostic factors in colorectal cancer. College of American Pathologists Consensus Statement. Arch Pathol Lab Med; 124: 979-994

Cornish JA, Tilney HS, Heriot AG, et al. (2007). A Meta-Analysis of Quality of Life for Abdominoperineal Excision of Rectum versus Anterior Resection for Rectal Cancer. Ann Surg Oncol; 14(7): 2056-2068

Daniels IR, Strassburg J \& Moran BJ. (2006). The need for future surgical low rectal cancer studies. Colorectal Disease; 8(3): 25-29

Dehni N, McFadden N, McNamara DA et al. (2003). Oncologic results following abdominoperineal resection for adenocarcinoma of the low rectum. Dis Colon Rectum; 46: 867-874.

Demetriades H, Kanellos I, Vasiliadis K et al. (2004). Age-associated prognosis following curative resection for colorectal cancer. Tech Coloproctol; 8(S1): 144-146

den Dulk M, Marijnen CAM, Putter H, et al. (2007). Risk factors for adverse outcome in patients with rectal cancer treated with an abdominoperineal resection in the total mesorectal excision trial. Ann Surg; 246: 83-90

Dresen RC, Peters EEM, Rutten HJT, et al. (2009). Local recurrence in rectal cancer can be predicted by histopathological factors. Eur J Surg Oncol; 35: 1071-1077

Eickenberg, HU, Amin M, Klompus W \& Lich R. (1976). Urologic complications following abdominoperineal resection. J Urol; 115: 180

Endreseth BH, Myrvold HE, Rumundstand P, et al. (2005). Transanal excision vs. major surgery for T1 rectal cancer. Dis Colon Rectum; 48: 1380-1388

Enker WE, Thaler HT, Cranor ML \& Polyak T. (1995). Total mesorectal excision in the operative treatment of carcinoma of the rectum. J Am Coll Surg; 181: 335-346

Fowler JW, Bremner DN \& Moffat L. (1978). The incidence and consequences of damage to the parasympathetic nerve supply to the bladder after abdominoperineal resection of the rectum for carcinoma. Br J Urol; 50: 95

Garcia-Aguilar H, Mellgren A, Sirivongs P, et al. (2000). Local excision of rectal cancer without adjuvant therapy. Ann Surg; 231: 345-351 
Harewood GC. (2005). Assessment of publication bias in the reporting of EUS performance in staging rectal cancer, Am J Gastroenterol; 100: 808-816

Heald RJ \& Karanjia ND. (1992). Results of radical surgery for rectal cancer. World J Surg; 16: 848-857

Heald RJ, Husband E \& Ryall R. (1982). The mesorectum in rectal cancer surgery - the clue to pelvic recurrence? Br J Surg; 69: 613-618

Heriot AG, Tekkis PP, Darzi A, et al. (2006). Surgery for local recurrence of rectal cancer. Colorectal Dis; 8: 733-747

Heriot AG, Hicks RJ, Drummond EG, et al. (2004). Does positron emission tomography change management in primary rectal cancer? A prospective assessment. Dis Colon Rectum; 47: 451-458

Hermanek P, Guggenmoos-Holzmann I \& Gall FP. (1989). Prognostic factors in rectal carcinoma. A contribution to the further development of tumour classification. Dis Colon Rectum; 32: 593-599

Hohenberger P, Schlag P, Kretzschmar U, et al. (1991). Regional mesenteric recurrence of colorectal cancer after anterior resection or left hemicolectomy: inadequate primary resection demonstrated by angiography of the remaining arterial supply. Int $J$ Colorectal Dis; 6: 17-23

Jeng-Kai J, Yang SH \& Lin JK. (2005). Transabdominal anastomosis after low anterior resection: A prospective, randomized, controlled trial comparing long-term results between side-to-end anastomosis and colonic J-pouch. Dis Colon Rectum; 48: 21002108

Kakodkar R, Gupta S \& Nundy S. (2006). Low anterior resection with total mesorectal excision for rectal cancer: functional assessment and factors affecting outcome. Colorectal Dis; 8: 650-656

Kanellos D, Pramateftakis MG \& Kanellos I. (2010). Standardization and time trends in laparoscopic colorectal surgery. Surg Endosc; 24(3): 726-727

Kanellos D, Pramateftakis MG, Vrakas G et al. (2010). Anastomotic leakage following low anterior resection for rectal cancer. Tech Coloproctol; 14: 35-37

Kanellos I, Vasiliadis K, Angelopoulos S, et al. (2004). Anastomotic leakage following anterior resection for rectal cancer. Tech Coloproctol; 8: s79-81

Kim HJ \& Wong WD. (2000). Role of endorectal ultrasound in the conservative management of rectal cancers. Semin Surg Oncol; 19: 358-366

Kim JS, Hur H, Kim NK, et al. (2009). Oncologic outcomes after radical surgery following preoperative chemoradiotherapy for locally advanced lower rectal cancer: abdominoperineal resection versus sphincter-preserving procedure. Ann Surg Oncol; 16(5): 1266-1273.

Kohler A, Athanasiadis S, Ommer A, et al. (2000). Long-term results of low anterior resection with intersphincteric anastomosis in carcinoma of the lower one-third of the rectum: analysis of 31 patients. Dis Colon Rectum; 43: 843-850

Kuhry E, Schwenk W, Gaupset R, et al. (2008). Long-term outcome of laparoscopic surgery for colorectal cancer: Cochrane systematic review of randomised controlled trials. Cancer Treat Rev; 34: 498-504

Kurt M, Ozkan L, Yilmazlar T, et al. (2005). Postoperative concomitant chemoradiotherapy in locally advanced rectal cancer. Hepatogastroenterology; 52(65): 1411-5 
Kwok H, Bissett IP \& Hill GL. (2000). Preoperative staging of rectal cancer. Int J Colorectal Dis; 15: 9-20

Law WL, Chu KW \& Choi HK. (2002). Randomized clinical trial comparing loop ileostomy and loop transverse colostomy for faecal diversion following total mesorectal excision. Br J Surg; 89: 704-708

Marakis G, Demetriades H, Ziogas D \& Kanellos I. (2009). Local excision for rectal cancersafety and efficacy challenges. Ann Surg Oncol; 16: 2369-2370

Marr R, Birbeck K, Garvican J et al. (2005). The modern abdominoperienal excision: the next challenge after total mesorectal excision. Ann Surg; 242: 74-82

Matthiessen P, Hallbook O, Rutegard J, et al. (2007). Defunctioning stoma reduces symptomatic anastomotic leakage after low anterior resection of the rectum for cancer. A randomized multicenter trial. Ann Surg; 246(2): 207-214

Matzel KE, Bittorf B, Gunther K, et al. (2003). Rectal resection with low anastomosis: functional outcome. Colorectal Dis; 5: 458-464

Mellegren A, Sirivongs P, Rothenberg DA, et al. (2000). Is local excision adequate therapy for early rectal cancer? Dis Colon Rectum; 43: 1064-1071

Meyerhardt JA, Tepper JE, Niedzwiecki D, et al. (2004). Impact of hospital procedure volume on surgical operation and long-term outcomes in high-risk curatively resected rectal cancer: findings from the Intergroup 0114 Study. J Clin Oncol; 22(1): 166-174

Miles WE. A method of performing abdomino-perineal excision for carcinoma of the rectum and of the terminal portion of the pelvic colon. (1971). Ca Cancer J Clin; 21: 361-364

Mohiuddin M, Hayne M, Regine WF et al. (2000). Prognostic significance of postchemoradation stage following preoperative chemotherapy and radiation for advanced/recurrent rectal cancers. Int J Radiat Oncol Biol Phys; 45: 1075-1080.

Nesbakken A, Nygaard K, Westerheim O, et al. (2002). Audit of intraoperative and early postoperative complications after introduction of mesorectal excision for rectal cancer. Eur J Surg; 168: 229-235

$\mathrm{Ng}$ SM, Leung KL, Lee JFY, et al. (2008). Laparoscopic-Assisted Versus Open Abdominoperineal Resection for Low Rectal Cancer: A Prospective Randomized Trial. Ann Surg Oncol; 15(9): 2418-2425

Nicholls RJ \& Tekkis PP. (2008). Multidisciplinary treatment of cancer of the rectum: a European approach. Surg Oncol Clin N Am; 17: 533-551.

Nicholls RJ. (1991). Surgical treatment of adenomas. World J Surg; 15: 20-24

Nissan A, Guillem JG, Paty PB et al. (2001). Abdominoperineal resection for rectal cancer at a specialty center. Dis Colon Rectum; 44: 27-36.

Nugent KP, Daniels P, Stewart B, et al. (1999). Quality of life in stoma patients. Dis Colon Rectum; 42: 1569-1574

Otchy D, Hyman NH, Simmang C, et al. (2004). Practice Parameters for Colon Cancer. The American Society of Colon and Rectal Surgeons. Dis Colon Rectum; 47: 1269-1284

Peparini N, Maturo A, Di Matteo FM, et al. (2006). Long-term survival and recurrences after total nerve-sparing surgery for rectal cancer. Hepatogastroenterology; 53(72): 850-853

Piso P, Dahlke MH, Mirena P, et al. (2004). Total mesorectal excision for middle and lower rectal cancer: a single institution experience with 337 consecutive patients. J Surg Oncol; 86: 115-121. 
Pramateftakis MG, Kanellos D \& Kanellos I. (2010). Progress in rectal cancer staging and treatment. Tech Coloproctol; 14(1): 29-31

Pramateftakis MG, Vrakas G, Hatzigianni P, et al. (2010). The handsewn anastomosis after colon resection due to colonic cancer. Tech Coloproctol; 14(1): 57-59

Ptok H, Marusch F, Meyer F, et al. (2007). Impact of anastomotic leakage on oncological outcome after rectal cancer resection. Br J Surg; 94: 1548-1554

Pugliese R, Di Lernia S, Sansonna F, et al. (2009). Laparoscopic resection for rectal adenocarcinoma. Eur J Surg Oncol; 35(5): 497-503

Quirke P \& Dixon MF. (1988). The prediction of local recurrence in rectal adenocarcinoma by histopathological examination. Int J Colorectal Dis; 3: 127-131

Rasmussen OO, Petersen IK \& Christiansen J. (2003). Anorectal function following low anterior resection. Colorectal Dis; 5: 258-261

Rees JR, Carney L, Gill TS, et al. (2004). Management of recurrent anastomotic stricture and iatrogenic stenosis by circular stapler. Dis Colon Rectum; 47: 944-947

Rothenberger DA \& Wong WD. (1992). Abdominoperineal resection for adenocarcinoma of the low rectum. World J Surg; 16: 478-485

Rullier E, Laurent C, Bretagnol, et al. (2005). Sphincter-saving resection for all rectal carcinomas: the end of the 2-cm distal rule. Ann Surg; 241(3): 465-469

Rullier E, Cunha AS, Coudere P, et al. (2003). Laparoscopic intersphincteric resection with coloplasty and coloanal anastomosis for mid and low rectal cancer. Br J Surg; 90: $445-451$

Rullier E, Cunha AS, Coudere P, et al. (1999). Intersphincteric resection with excision of internal anal sphincter for conservative treatment of very low rectal cancer. Dis Colon Rectum; 42: 1168-1175

Rullier E, Laurent C, Garrelson JL, et al. (1998). Risk factors for anastomotic leakage after resection of rectal cancer. Br J Surg; 85: 355-358

Saito N, Sugito M, Ito M, et al. (2009). Oncologic outcome of intersphincteric resection for very low rectal cancer. World J Surg; 33: 1750-1756

Sangwan YP \& Solla JA. (1998). Internal anal sphincter: advances and insights. Dis Colon Rectum; 41: 1297-1311

Schwenk W, Neudecker J, Raue W, et al. (2006). "Fast-track" rehabilitation after rectal cancer resection. Int J Colorectal Dis; 21: 547-553

Staudacher C, Vignali A, Di Palo S, et al. (2007). Laparoscopic vs Open Total Mesorectal Excision in unselected patients with rectal cancer: Impact on early outcome. Dis Colon Rectum; 50: 1324-1331

Sugarbaker PH. (1996). Rectovaginal fistula following low circular stapled anastomosis in women with rectal cancer. J Surg Oncol; 61: 155-158

Taflampas P, Christodoulakis M \& Tsiftsis D. (2009). Anastomotic leakage after low anterior resection for rectal cancer: Facts, Obscurity, and Fiction. Surg Today; 39: 183-188.

Tekkis PP, Heriot AG, Smith J, et al. (2005). Comparison of circumferential margin involvement between restorative and nonrestorative resections for rectal cancer. Colorectal Dis; 7: 369-374

Tilney HS \& Tekkis PP. (2007). Extending the horizons of restorative rectal surgery: intersphincteric resection for low rectal cancer. Colorectal Dis; 10: 3-16

Tsarkov P. (2005). Abdominoperineal resection. In: Rectal Cancer: New frontiers in diagnosis, treatment and rehabilitation, Dilaini G.G., 157-165, Springer 
Vordermark D, Sailer M, Flentje M, et al. (1999). Curative-intent radiation therapy in anal carcinoma: quality of life and sphincter function. Radiother Oncol;52: 239-243

Vrakas G, Pramateftakis MG, Kanellos D, et al. (2010). Defunctioning ileostomy closure following low anterior resection by chemotherapy. Tech Coloproctol; 14(S1): 77-78

Wagman R, Minsky BD, Cohen AM, et al. (1999). Conservative management of rectal cancer with local excision and postoperative adjuvant therapy. Int J Radiat Oncol Biol Phys; 44: 841-846.

Wibe A, Rendedal PR, Svenson E, et al. (2002). Prognostic significance of circumference resection margin following total mesorectal excision for rectal cancer. Br J Surg; 89: 327-334

Wiggers T, Jeekel J, Arends JW, et al. (1988). No-touch isolation technique in colon cancer: a controlled prospective trial. Br J Surg; 75: 409-415

Williams NS, Dixon MF \& Johnston D. (1983). Reappraisal of the 5-cm rule of distal excision for carcinoma of the rectum: a study of distal intramural spread and of patients' survival. Br J Surg; 70: 150-154

Yamada K, Ogata S, Saiki Y, et al. (2009). Long-term results of intersphincteric resection for low rectal cancer. Dis Colon Rectum; 52: 1065-1071

Young-Fadok TM, Wolff BG, Nivatrongs S, et al. (1998). Prophylactic oophorectomy in colorectal carcinoma: preliminary results of a randomized, prospective trial. Dis Colon Rectum; 41: 277-285 


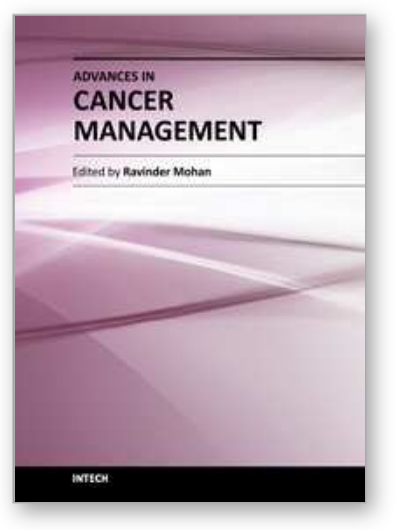

\author{
Advances in Cancer Management \\ Edited by Prof. Ravinder Mohan
}

ISBN 978-953-307-870-0

Hard cover, 278 pages

Publisher InTech

Published online 27, January, 2012

Published in print edition January, 2012

Cancer is now the most common cause of death in the world. However, because of early diagnosis, better treatment, and advanced life expectancy, many cancer patients frequently live a long, happy, and healthy life after the diagnosis- and often live as long as patients who eventually do not die because of cancer. This book presents newer advances in diagnosis and treatment of specific cancers, an evidence-based and realistic approach to the selection of cancer treatment, and cutting-edge laboratory developments such as the use of the MALDI technique and computational methods that can be used to detect newer protein biomarkers of cancers in diagnosis and to evaluate the success of treatment.

\title{
How to reference
}

In order to correctly reference this scholarly work, feel free to copy and paste the following:

Pramateftakis Manousos-Georgios, Papadopoulos Vasileios, Michalopoulos Antonios, Spanos Konstantinos, Tepetes Konstantinos and Tsoulfas Georgios (2012). Rectal Cancer - Staging and Surgical Approach, Advances in Cancer Management, Prof. Ravinder Mohan (Ed.), ISBN: 978-953-307-870-0, InTech, Available from: http://www.intechopen.com/books/advances-in-cancer-management/rectal-cancer-staging-and-surgicalapproach-

\section{INTECH}

open science | open minds

\section{InTech Europe}

University Campus STeP Ri Slavka Krautzeka 83/A 51000 Rijeka, Croatia Phone: +385 (51) 770447 Fax: +385 (51) 686166 www.intechopen.com

\section{InTech China}

Unit 405, Office Block, Hotel Equatorial Shanghai No.65, Yan An Road (West), Shanghai, 200040, China 中国上海市延安西路65号上海国际贵都大饭店办公楼 405 单元 Phone: +86-21-62489820

Fax: +86-21-62489821 
(C) 2012 The Author(s). Licensee IntechOpen. This is an open access article distributed under the terms of the Creative Commons Attribution 3.0 License, which permits unrestricted use, distribution, and reproduction in any medium, provided the original work is properly cited. 